\title{
GUBERNAMENTALIDAD Y PODER DE POLICÍA: la articulación de un modelo de policiamiento dual en Buenos Aires, 2004-20071
}

\author{
Alina Lis Rios*
}

\begin{abstract}
Este trabalho analisa a emergência e o funcionamento da Guarda Urbana (GU) da cidade de Buenos Aires, (2004 e 2007), como policia comunitária resultante do reordenamento da autonomia do governo local. Este processo gerou um modelo dual de policiamento na cidade, representado, pela (GU) em contraposição às forças de segurança do nacionais, mais verticalizadas e centralistas. O artigo investiga as implicações da GU na disputa pelo poder da polícia na cidade e uma forma histórica particular de construção da segurança: a segurança cidadã. Esta dualidade representa uma solução de compromisso possível entre os interesses nacionais e os da cidade. O artigo conclui com reflexões sobre a crise desse modelo dual, a redefinição do problema da segurança e as demandas de uma "Polícia própria", no âmbito local. Destaca que é na dualidade da segurança que se concebe uma Guarda Urbana, como policiamento de proximidade, que complementa, mas não substitui a antiga polícia.

PALAVRAS-CHAVE: governamentabilidade, poder de policía, seguridad ciudadana, poder local, Buenos Aires.
\end{abstract}

\section{PRESENTACIÓN}

Hacia fines del año 2004 tiene lugar la creación de la Guardia Urbana de la Ciudad de Buenos Aires (GU), un cuerpo de agentes de carácter civil, no militar e, incluso no armado, al que se le atribuyeron funciones relativas a la seguridad y que dependía política, funcional y administrativamente del poder ejecutivo del Gobierno de la Ciudad de Buenos Aires. Desde la federalización de la Ciudad en 1880, el gobierno local no había contado con un cuerpo de seguridad propio. En el territorio de la Ciudad de Buenos Aires, Capital Federal de la República Argentina, la seguridad era asunto a atender exclusivamente por fuerzas de seguridad dependientes del gobierno nacional (la PFA, Gendarmería Nacional y Prefectura Naval Ar-

* Socióloga. Doutoranda em Ciências Sociais pela Universidade de Buenos Aires (UBA). Bolsista do CONICET. Pte J. E. Uriburu 950, $6^{\circ}$ (CP 1114) Buenos Aires, Argentina. alinalrios@yahoo.com.ar

${ }^{1}$ Este artículo presenta algunos de los planteos que la autora trabaja en su Tesis de Maestría, dirigida por Victoria Rangugni y Juan Pegoraro. gentina). ${ }^{2}$ Una Ley Nacional, Ley 24.588, conocida como "Ley Cafiero", en su Art. $7^{\circ}$, restringe las posibilidades del Gobierno de la Ciudad de contar con una fuerza policial propia, operando como "garantía de los intereses de la Nación" en la Ciudad de Buenos Aires, en tanto sigue siendo esta ciudad Capital Federal. Este Art. $7^{\circ}$ estuvo vigente hasta agosto de 2007, cuando es modificado por el Congreso Nacional. La vigencia de esta Ley marca estructuralmente lo que fue la experiencia de la GU y la articulación en esta Ciudad de lo que hemos llamado un modelo de policiamiento dual.

La postulación de este modelo de policiamiento dual no se trata de la postulación de un modelo a priori, por el contrario, ha surgido a

2 En la República Argentina las fuerzas de seguridad comprenden: Gendarmería Nacional, Prefectura Naval, el Servicio Penitenciario Federal y los sistemas penitenciarios provinciales y las Fuerzas Policiales - la Policía Federal Argentina, la Policía de Seguridad Aeroportuaria y las policías provinciales. Salvo estas últimas y los sistemas penitenciarios provinciales que, como su nombre lo indica, dependen del poder ejecutivo de cada una de las provincias, el resto de las fuerzas de seguridad dependen de la Secretaria de Seguridad Interior del Ministerio de Justicia, Seguridad y Derechos Humanos de la Nación. (Véase: www.jus.gov.ar/el-ministerio/mision/secretaria-deseguridad-interior.aspx; y, para consultar, la organización de la Policía Federal Argentina: www.policiafederal.gov.ar).

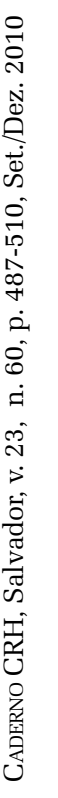


partir de nuestra investigación. ${ }^{3}$ Nuestro horizonte de trabajo es el análisis de las prácticas policiales y relaciones de gobierno que constituyen, en un determinado momento y lugar, el ejercicio del poder de policía. ${ }^{4}$ Pues entendemos que las formas de policiamiento son siempre situadas, históricas, y nuestro análisis pretende ser consecuente al respecto. Lo que lleva a poner en primer plano el lazo entre gobierno y policía, es decir, entre el "arte de gobernar” (los dispositivos técnicos emplazados y puestos a funcionar, su racionalidad estratégica y sus disposiciones tácticas) y el ejercicio del poder de policía. Porque la manera en que se define el gobierno, en qué debe consistir y sobre qué objetos debe recaer es algo que no se mantiene invariable a lo largo de la historia. Y conforme se producen variaciones al respecto, también varían las consideraciones acerca de los modos del ejercicio del poder de policía que se consideren adecuados al "buen gobierno".

Un elemento central de nuestro abordaje es la introducción de la noción foucaultiana de gobierno, y la serie asociada: gubernamentalidad, racionalidad política, tecnología de gobierno, conceptos de los que nos hemos apropiado de manera no ortodoxa e incluso, tal vez, poco reverente. Estos conceptos, tal como son desarrollados por Foucault (Foucault, [1967], 1996, 2001a, 2002, 2004a, 2004b), ${ }^{5}$ implican una

${ }^{3}$ La noción de modelo es recuperada de manera crítica, intentando romper con aquellas perspectivas formalistas o normativas, a partir de las que se despliegan formas de argumentación que se caracterizan por poner el contenido como contingente para luego prescindir de él teóricamente (Offe, 1990, p.72-73)

${ }^{4}$ Recuperando esta mirada puesta en las prácticas efectivas, desde el Programa de Estudios sobre el Control Social (PECOS) del Instituto de Investigaciones Gino Germani de la Universidad de Buenos Aires, nuestro horizonte de trabajo es el análisis de las prácticas policiales en relación con la conformación de una experiencia histórica que articula de manera singular formas de saber, relaciones de poder y formas de subjetivación, en su vinculación con la problematización de la (in)seguridad. Las contribuciones principales están reunidas en nuestro trabajo A la inseguridad la hacemos entre todos. Prácticas académicas, mediáticas y policiales (Galvani et al., 2010).

${ }^{5}$ Se trata esta de una exposición sumamente esquemática que no refleja la densa y compleja trama teórica en que se inscriben estos conceptos, que a lo largo de su desarrollo no estuvieron exentos de desplazamientos, redefiniciones y reinscripciones; pero este no es el lugar de desarrollarlos, aunque pueda ser una de las tareas a las que debamos abocarnos en el curso de nuestro trabajo doctoral. forma de interrogación sobre las relaciones de poder con énfasis en la perspectiva relacional (Foucault, [1967], 2002 2001). ${ }^{6}$ Gobernar no significa hacer valer la propia voluntad frente a una oposición (algo que está por fuera y se resiste) de manera unidireccional, sino que también, en relación a esta noción de gobierno, el ejercicio del poder es concebido como "una estructura total de acciones dispuestas para producir posibles acciones: incita, induce, seduce, facilita o dificulta" (Foucault, 2001a, p.253). Se trata de una producción de conductas, esto es la conducción de las conductas (2001c, p.1033). ${ }^{7}$

La gubernamentalidad es lo que se configura como el campo estratégico en el que se definen las formas posibles del gobierno de los hombres (en tanto "conducción de las conductas"). Campo estratégico que no es otra cosa que el resultado del juego que se establece entre las múltiples relaciones de poder. En tanto tal, no constituye una estructura, sistema fijo de relaciones por referencia al cual se organizan las prácticas. Por el contrario, se resalta una relación inversa entre las prácticas (concretas y singulares) por referencia a las cuales puede identificarse la conformación de cierta totalización, o, más precisamente, se trata de una "géneralité singulière" [generalidad singular] ${ }^{8}$ del orden de

${ }^{6}$ El texto mencionado constituye una referencia bibliográfica canónicamente aceptada acerca de la concepción foucaultiana del poder, la cual queda allí expresada en cuatro reglas o "prescripciones de prudencia", a saber: 1) regla de inmanencia; 2 ) regla de las variaciones continuas; 3) regla del doble condicionamiento; y 4) regla de la polivalencia táctica de los discursos (Foucault, [1967], 002, p.119-125).

En el original: “Quant à l' étude de la 'gouvernementalité', elle répondait à un double objectif: faire la critique nécessaire des conceptions courantes du 'pouvoir' (plus ou moins confusément pensé comme un système unitaire, organisé autour d' un centre qui en est en même temps la source, et qui est porté par sa dynamique interne à s' étendre toujours); l'analyser au contraire comme un domaine de relations stratégiques entre des individus ou des groupes-relations qui ont pour enjeu la conduit de l' autre ou des autres, et qui ont recours, selon le cas, selon les cadres institutionnels où elles se développent, selon les groupes sociaux, selon les époques, à de procédures et techniques diverses..." (la traducción es nuestra).

${ }^{8}$ Estas son las palabras usadas por Michel Foucault en un manuscrito sobre la gubernamentalidad, insertado entre las clases del 21 de febrero y el 7 de marzo de 1979 del curso Nacimiento de la Biopolítica, citado por Michel Senellart en la "Situación del curso" de la edición de los Cursos de 1977-1978, Seguridad, territorio, población (Senellart, 2004, p.407) 
los efectos de esas prácticas, que son prácticas y relaciones múltiples, móviles, variables y relativamente aleatorias.

Respecto de esta multiplicidad de prácticas y relaciones de gobierno, en tanto constituyen un nivel de generalidad, nos interesa especificar tres dimensiones analíticas: el de las racionalidades políticas, el de las tecnologías de gobierno (la articulación de las múltiples prácticas de gobierno y dispositivos de poder) y el de las tácticas y estrategias en las que se inscriben. Es así que nos es posible considerar la GU en tanto tecnología de gobierno, es decir, en tanto conjunto de técnicas de gobierno, desde aquellas que se ponen en marcha para su consitutución a aquellas que supone su puesta en funcionamiento. Conjunto que supone un entramado no meramente azaroso o aleatorio sino forjado en torno a una cierta racionalidad política que plantea los lineamientos de lo que se considera debe ser el "buen gobierno" de la seguridad.

Estas tres dimensiones analíticas mencionadas - racionalidades políticas, tecnologías y tácticas y estrategias - son tres maneras de considerar una multiplicidad de prácticas concretas en tanto configuran un nivel de generalidad que hemos llamado gubernamentalidad. ${ }^{9}$ Nos es preciso resaltar que sólo se trata de distinciones analíticas; no hay, propiamente hablando, racionalidad posible sino a partir del funcionamiento singular de una multiplicidad de técnicas y procedimientos; no hay tampoco ninguna tecnología de la que no sea posible reconocer los principios de la racionalidad que rigen su funcionamiento $y$ articulación con otras técnicas y procedimientos, ni ninguna técnica que tenga una existencia más allá de apropiaciones tácticas en los marcos singulares y locales de una relación estratégica. ${ }^{10}$

${ }^{9}$ A riesgo de multiplicar promesas, advertimos que una crítica de la utilización que hacemos del concepto de gubernamentalidad, sus alcances y limitaciones, y sus contrapuntos en relación a la recuperación que de él hacen los governmentality studies (Barry et al., 1996; Dean, 1999; Gordon, 1991) serán elementos a trabajar en nuestra tesis doctoral.

${ }^{10}$ Nuestra investigación, más amplia de lo que aquí se presenta, aborda fundamentalmente la construcción estratégica de posicionamientos políticos en el escenario local, sobre todo la construcción del enfrentamiento "Nación-
Pero entonces, y en segundo lugar, merece la pena detenernos y especificar lo que queremos realzar con esta diferenciación analítica.

Con la dimensión relativa a la tecnología de gobierno, remitimos a las prácticas en tanto instrumentos técnicos del ejercicio del poder, mecanismos prácticos y reales, locales y aunque aparentemente nimios (o por ello) que instrumentalizan el ejercicio del poder, produciendo, con su puesta en funcionamiento, unos determinados efectos. Una tecnología no es exactamente una institución o un aparato. No se corresponde con lo institucional. Es más y es menos que eso. Es más porque, aunque una cierta institución puede constituirse como una tecnología de gobierno, no obstante otras tecnologías pueden no cristalizar en una organización institucional. Es menos porque una institución puede acoger la puesta en funcionamiento de una multiplicidad de técnicas articuladas en tecnologías diversas, que incluso pueden variar con el tiempo en la historia de la institución. Pero sobre todo, cuando se analizan las prácticas en tanto tecnologías de gobierno, lo importante no son sólo las determinaciones y prescripciones institucionales, sino las relaciones de fuerza que atraviesan y ponen en funcionamiento los mecanismos que constituyen esas prácticas que cristalizan en esas instituciones. ${ }^{11}$

A nuestro entender, entre técnicas y tecnologías, la diferencia es, podríamos decir, del orden de la agregación estratégica. Las técnicas son los elementos más simples en los que se pueden descomponer los procedimientos o los mecanismos de poder. La noción de tecnología alude al nivel de la articulación de técnicas, articulación orientada a la producción de unos determinados efectos, aunque es preciso tener en cuenta que se trata de una direccionalidad no

Ciudad”, pero es una dimensión que no hemos desplegado en este trabajo.

${ }^{11}$ En este sentido, Foucault señala, a propósito de la "disciplina", que esta no puede identificarse ni con una institución, ni con un aparato, sino que constituye "un tipo de poder, una modalidad para ejercerlo, implicando todo un conjunto de instrumento, de técnicas, de procedimientos, de niveles de aplicación, [...] es una tecnología. "(Foucault, 2000, p. 218). 
intencionada por un sujeto (Foucault, 2003). Y, por otra parte, es sobre este nivel de la integración estratégica de técnicas múltiples que pueden tener lugar la práctica de reflexión y pensamiento que las toma por objeto (racionalidad política).

Ahora bien, referirnos a la Guardia Urbana como tecnología de gobierno no implica definirla como una tecnología acabada y cerrada sobre sí misma. Antes bien, implica identificar el conjunto de técnicas comprendidas en su puesta en funcionamiento y analizar la articulación de estas técnicas con otras articulaciones y puntos de apoyos que se ordenan de una manera particular, dando por resultado la producción de unos determinados efectos. Es esta articulación y la producción de tales efectos lo que se configura como objeto de análisis. Se trata de pensar las distintas técnicas involucradas en la creación y puesta en funcionamiento de la Guardia Urbana como "técnicas con valor operativo en procesos múltiples" (Foucault, 2004b, p.123). En otras palabras, se trata de pensar esas técnicas en su vinculación con otros procesos respecto a los cuales son presentadas como resoluciones operativas frente a los problemas que se identifican.

Planteábamos, al principio, la centralidad que tiene en nuestro planteo la historización del ejercicio del poder de policía, en su vinculación con un "arte de gobernar". Ahora bien, esta relación gobierno-policía encuentra una mediación fundamental que, parafraseando a Foucault (2004b), hemos llamado la gubernamentalización de la seguridad: es decir, el emplazamiento de la seguridad como fin y objeto de gobierno. Foucault postula la gubernamentalización del Estado en el sentido de que "son las tácticas de gobierno las que permiten definir a cada momento lo que debe depender del Estado y lo que no debe depender de él, lo que es público y lo que es privado, lo que es estatal y lo que es no estatal." (2004b, p.112-113). ${ }^{12}$ De manera análoga, proponemos

${ }^{12}$ En el original: “...ce sont les tactiques de gouvernement que, à chaque instant, permettent de définir ce qui doit relever de l'État et ce qui ne doit pas en relever, ce qui est public et ce qui est privé, ce qui est étatique et ce qui est non étatique", (la traducción es nuestra). pensar la "gubernamentalización” de la seguridad, en la medida en que son las tácticas de gobierno las que hacen posible una delimitación del problema de la seguridad y de las prácticas que deben articularse para enfrentarlo. Qué es la seguridad y qué ha de ser el "buen gobierno" comienzan a definirse de manera íntimamente asociada. De esta manera, la seguridad comienza a emerger como objeto de gobierno, y, correlativamente, el gobierno se legitima cada vez más como cuestión securitaria. La seguridad se ha convertido en objeto de gobierno, punto de aplicación y objeto a producir. Por la seguridad y para la seguridad (su construcción como problema y la implementación de los medios para su solución) es que se establecen las relaciones de gobierno.

Así, nuestra tesis principal es que el desarrollo de los procesos de emergencia y puesta en funcionamiento de la GU, y, posteriormente, también su disolución, está ligado a una particular forma histórica de construcción del problema de la seguridad en relación a la cual se reordenan y redefinen las relaciones de gobierno $\mathrm{y}$, en consecuencia, también las formas de policiamiento.

Estudiamos, entonces, la emergencia de la GU y su puesta en funcionamiento en su relación con la problematización de la seguridad y la redefinición de la cuestión del gobierno en la Ciudad de Buenos Aires, en el período que se abre a partir de la autonomización de esta ciudad, cristalizada institucionalmente en la reforma de la Constitución Nacional realizada en el año 1994 y en la Constitución de la Ciudad de Buenos Aires sancionada en 1996.

\section{ESTRATEGIA METODOLÓGICA}

El debate en torno al ejercicio del poder de policía que se desarrolla en la Ciudad de Buenos Aires durante el año 2004 se plantea como superficie de emergencia de la GU. Por ello, proponemos un análisis del desarrollo de esta disputa que nos permita recuperar los ele- 
mentos que constituyen la racionalidad política que la atraviesa, es decir, las formas de pensar en y desde las relaciones de gobierno allí puestas en juego. Para ello, tomamos en consideración una serie de documentos que remiten a esta cuestión: el proyecto de creación de la Guardia Urbana elaborado por la Secretaría de Justicia y Seguridad del Gobierno de la Ciudad de Buenos Aires y el decreto en el cual finalmente cristaliza su creación..$^{13}$ Pero, además, nos serviremos de un segundo conjunto de documentos contemporáneos a los anteriores, constituido por una serie de proyectos de ley que, durante el año 2004, fueron presentados en la Legislatura de la Ciudad de Buenos Aires. En la base de datos de $\mathrm{CEDOM}^{14}$ se registra, durante el año 2004, la presentación de siete proyectos de ley para la creación de policías en la Ciudad, lo que da cuenta de que el tema de la seguridad y de la creación de un cuerpo de seguridad es preocupación de los legisladores porteños.

En relación a la puesta en funcionamiento de la GU, analizamos también una serie de documentos institucionales que comprende las resoluciones administrativas que rigen el funcionamiento de la $\mathrm{GU}^{15} \mathrm{y}$ otros documentos institucionales de circulación restringida a los que accedimos por medio de informantes clave. ${ }^{16}$ Se consideraron, además, los informes de gestión publicados en el portal web del Gobierno de la Ciudad de Buenos Aires, área "Justicia y Seguridad"; ${ }^{17}$ también se tomaron en

${ }^{13}$ Decreto $n^{\circ} 2124 / 04$. Decreto de Creación de la Guardia Urbana, publicado en el Boletín Oficial de la Ciudad de Buenos Aires n 2074 del 24/11/2004.

${ }^{14}$ El CEDOM, es la Dirección General Centro de Documentación y Archivo Legislativo de la Ciudad Autónoma de Buenos Aires, organismo que sigue siendo conocido por las siglas de su nombre original (Centro de Documentación Municipal), que cambió conforme al nuevo estatus jurídico de la ciudad (http://www.cedom.gov.ar).

${ }^{15}$ Entre ellas: Resolución 175/2006. Cuerpo de la Guardia Urbana. Funciones, publicado en el Boletín Oficial de la Ciudad de Buenos Aires no 2393 del 7/3/2006; Resolución 221/GCBA/SG/98, publicada en Boletín Oficial de la Ciudad de Buenos Aires no 592 del 15/12/1998.

${ }^{16}$ Así el Proyecto de Creación de la Guardia Urbana; la ficha de selección de personal utilizada para el registro de las capacidades evaluadas mediante la técnica del Assesment Center; y el Plan de Capacitación para la Guardia Urbana. Contenidos mínimos. Subsecretaría de Seguridad Urbana. GCBA.

${ }^{17}$ Véase: www.buenosaires.gov.ar/areas/gobierno/noticias/ consideración un total de 15 noticias referidas a la Guardia Urbana, publicadas entre noviembre de 2004 y febrero de 2008. Finalmente, se realizaron tres entrevistas a funcionarios del Gobierno de la Ciudad de Buenos Aires involucrados en el despliegue de esta experiencia. Fueron entrevistados también quince agentes de este cuerpo de seguridad que cumplían funciones operativas. Asimismo, fueron entrevistados dos otros actores intervinientes en la selección de personal (un empleado administrativo de la Dirección de Guardia Urbana y un operador de la AMIA, organización no gubernamental que tiene destacada participación en este proceso de selección del personal) y dos trabajadores de la Dirección de Políticas de Seguridad del Gobierno de la Ciudad de Buenos Aires involucrados en el proceso de capacitación de los guardias urbanos,$^{18}$ quienes participaron tanto del diseño del programa de capacitación como en el dictado de los cursos a los agentes ingresantes al cuerpo.

\section{EMERGENCIA DE LA GUARDIA URBANA}

\section{La autonomía y la disputa por la definición del ejercicio del poder de policía}

La reforma de la que es objeto la Constitución Nacional de la República Argentina en 1994, a partir del texto del artículo 129, reconoce a la Ciudad de Buenos Aires el estatus de Ciudad Autónoma, es decir, un régimen de gobierno que implica plena autonomía de los ciudadanos de la Ciudad para elegir al Jefe de Gobierno, investidura del poder ejecutivo local, así como a sus representantes legisladores. Dos años después, en octubre de 1996, poniendo en ejercicio esta autonomía, se sanciona la Constitución de la Ciudad de Buenos Aires. Mucho se discute por aquellos años acerca del

${ }^{18}$ La tarea de codificación y sistematización de este material documental fue realizada con la asistencia de ATLAS.ti, uno de los CAQDAS - Computer Assisted Qualitative Data Analysis Software - más utilizados en la actualidad, cuya función es facilitar el análisis cualitativo de grandes volúmenes de datos textuales. 
alcance y de la naturaleza de esta autonomía. ${ }^{19}$ Más allá de la complejidad jurídica de estos debates, a nosotros nos interesa resaltar el carácter político de esta cuestión. El subtítulo del trabajo de Sabsay (1996), "Alcance de la autonomía acordada..." nos pone frente al hecho de que esta autonomía lograda es expresión de una relación de fuerzas, es decir que hay que reconocerla como objeto de redefiniciones políticas. Por lo que, si los actores locales pueden denunciar su carácter de “autonomía restringida”, y entre las restricciones destacar el rol desempeñado por la Ley Cafiero, hay que reconocer también que esta restricción no es un estado definitivo. Por el contrario, es un momento en el devenir de unas relaciones de fuerza, porque la autonomía es algo en construcción.

Y en relación al ejercicio del poder de policía, la construcción de la autonomía, su ampliación o refuerzo, coincidirá con un proceso que tiende a erosionar el desacople entre gobierno municipal y uso de la fuerza pública que la vigencia de la Ley Cafiero pone de manifiesto, reproduciendo una situación que se configura a partir de la federalización de Buenos Aires: la Policía (la Policía de la Ciudad primero y la Policía Federal Argentina después) se despliega como tecnología de gobierno prácticamente independiente del poder municipal, constituyéndose en instrumento del gobierno nacional, por medio del cual se refuerza la subordinación de la ciudad a la nación. Un ejemplo de esta restricción de las prerrogativas del gobierno municipal es la vigencia del Código de Procedimientos en lo Criminal para la Capital y Territorios Nacionales, que establece la facultad del Jefe de Policía de dictar los Edictos de Policía, es decir, de establecer la norma de su propia actuación.

Un hito en relación a la articulación entre gobierno municipal y ejercicio del poder de policía lo constituye la sanción del Código de Convivencia de la Ciudad de Buenos Aires, sancionado por la Legislatura de la Ciudad en 1998. La sanción de este código va a significar el fin de los edictos

${ }^{19}$ Se discuten sobre todo las implicancias institucionales y jurídicas de esta autonomía (Argüello, 1995, 2001; De Geovanni, 1995; González Bergés, 1995; Sabsay, 1996). policiales y, por ello mismo, el comienzo de una nueva relación entre la policía y el gobierno local, el primer quiebre de esa disociación uso de la fuerza-gobierno local.

Nos detendremos en un análisis de la configuración de la disputa que se despliega en torno al ejercicio del poder de policía, especialmente en el contexto de creación de la Guardia Urbana. Más allá de su relevancia funcional, es en torno al funcionamiento, legitimidad y utilidad de este cuerpo que, aún en años posteriores, se articulará la disputa acerca del ejercicio del poder de policía en la Ciudad. Además, durante ese mismo año, se presentaron varios proyectos legislativos referidos al tema. En relación a estas intervenciones, puede reconstruirse una disputa que se configura tomando como uno de sus ejes la definición del ejercicio del poder de policía en la ciudad de Buenos Aires. ${ }^{20}$ En relación a los discursos que se organizan en torno a la disputa por la definición del ejercicio del poder de policía en la Ciudad de Buenos Aires, podemos observar la reactualización de la distinción histórica respecto de dos modelos de policiamiento contrapuestos. Por un lado, aquel que puede identificarse como el "modelo francés", fuertemente asociado a la formación de un Estado burocrático centralizado, y, por otro lado, el "modelo inglés", un esquema descentralizado de policía comunitaria. ${ }^{21}$

El debate local sobre el ejercicio del poder de policía se estructura reactualizando esta contraposición entre un modelo novedoso,

${ }^{20}$ Acerca de la cuestión del ejercicio del poder de policía, pueden advertirse las múltiples resonancias de esta discusión en otras latitudes. Tanto en Europa como en Estados Unidos y Canadá en América del Norte, el tema del gobierno de la seguridad y el diseño de políticas securitarias ha puesto en sus primeros planos la cuestión policial. En los distintos contextos, las preocupaciones que atraviesan estos debates suelen ser diferentes (en Europa, se advierte fuertemente la tensión entre la configuración de un espacio global europeo, que se corporiza en la Unión Europea, por un lado, y las autonomías locales, mientras que, en Estados Unidos y Canadá, o incluso Gran Bretaña, la principal preocupación está asociada al desarrollo del vínculo policía-ciudadanía).

${ }^{21}$ Esta contraposición la podemos encontrar desarrollada en la bibliografía especializada en la materia, asociada a las diferencias que pueden identificarse en los procesos de construcción de los Estados Nacionales que dan su nombre a cada uno de estos modelos (Maier, 1996; Recasens i Brunet, 1989). 
propuesto como innovación tecnológica adaptada a la complejidad del problema que se debe atender, respecto de un modelo más tradicional, en el que se inscribe tanto el funcionamiento de la Policía Federal Argentina como de la Policía de la Provincia de Buenos Aires. En los documentos que analizamos, este modelo alternativo se encarna en la figura de la policía comunitaria o de proximidad (descentralizada, dependiente de administraciones locales, decididamente civil, en la que las técnicas de disuasión y persuasión son más importantes que el orden jerárquico, el mando y la obediencia). Por contraposición, el modelo policial que podemos definir como tradicional queda definido respecto a los rasgos de organización jerárquica, centralista, autoritaria, uso abusivo de la fuerza, y la falta de control político y ciudadano sobre su funcionamiento.

Esta contraposición puede sistematizarse en torno a tres ejes o nudos problemáticos que la estructuran:

a. Reivindicación de lo local como nivel de pertinencia del gobierno. Las propuestas de creación de una nueva institución policial se plantean como una alternativa frente a la respuesta vertical y centralizada que constituyen las formas policiales tradicionales (tal como son definidas en esas mismas propuestas) frente al problema de la seguridad. Por el contrario se reivindica la eficacia de las "soluciones locales para problemas locales".

Desde esta perspectiva, eficacia y eficiencia son los distintivos del "buen gobierno". La eficacia tiene que ver con la identificación del problema y el hallazgo de una solución adecuada, es decir, se trata de tener las herramientas para identificar el verdadero problema y el origen y naturaleza del mismo. La herramienta o la técnica fundamental es lo que se denomina el diagnóstico local y comunitario, que comprende un juego de relación entre los vecinos y los funcionarios, que los "compromete" con la acción: participar, los primeros, escuchar, los segundos. Por su parte, la eficiencia refiere a la economía de la gestión, una economía que asegure el menor gasto con el mayor benefi- cio, e implica un conocimiento acabado de los recursos disponibles, pero también la capacidad de movilizarlos y de hacerlo hacia allí donde su utilidad es máxima. Eficacia y eficiencia se entrelazan y, para lograr una y otra, la fórmula es la proximidad, proximidad que es garantía de un saber sobre la naturaleza de un problema, pero también acerca de los recursos disponibles y que pueden ser movilizados para ensayar una solución. La construcción de un saber acerca del problema y de la situación locales son condición de posibilidad de la eficacia y la eficiencia, y tal saber no es posible sino en tanto se establezca una relación de proximidad con la comunidad y sus circunstancias.

Es en correspondencia con lo que venimos diciendo que aparece la dimensión de "lo local" en relación a la organización de un poder de policía $y$, en este sentido, son valorizadas las experiencias de policía comunitaria. La Guardia Urbana emerge enraizada en discursos sobre la racionalidad técnica del gobierno y la efectividad de lo local, que, como mencionáramos antes, hacen de la proximidad el atributo principal. En donde la eficacia estatal aparece dependiendo de la gestión por parte de actores que "conocen el problema". Nos encontramos ante una racionalidad política, una forma de pensar sobre $\mathrm{y}$ en las relaciones de poder que pone como centro y eje el gobierno local y autónomo de la seguridad.

b. La pretensión de un poder de policía más acá del uso de la fuerza. También es por referencia a las consideraciones respecto del uso de la fuerza que se define un modelo de policiamiento alternativo al tradicional. Este aspecto debe ser considerado en relación a las críticas de las que son objeto las fuerzas policiales tradicionales; nos referimos tanto a la Policía de la Provincia de Buenos Aires como a la Policía Federal Argentina. La crítica al funcionamiento de estas fuerzas se articula con la crítica por el papel desempeñado durante la dictadura, con la denuncia de violación de derechos humanos en democracia y con la preocupación por el problema de la (in)seguridad y la identificación del 
accionar policial como una de sus causas (Kessler, 2009; Mouzo; Galvani; Rios, 2009).

Es en este contexto que el modelo policial, que se define en los términos de una policía comunitaria, se contrapone al modelo policial tradicional en relación al uso de la fuerza. Por esta oposición, el modelo policial comunitario queda asociado a un uso racional de la fuerza. Esta racionalidad supone el cálculo de la menor fuerza necesaria. En razón de ello, la función policial por excelencia para este modelo no es la represión, sino la prevención y la promoción de determinadas conductas. Y, en contraposición al uso de la fuerza, se prevén otras técnicas de intervención que se orientan por la pretensión de construcción de consenso. No sólo suponen la interacción de sujetos orientados por una racionalidad instrumental, sino que se prevé la posibilidad de una comunicación que transparente los medios y los fines, así como los intereses de los sujetos. Estas técnicas se engloban bajo lo que se denomina "resolución alternativa de conflictos", que implica la posibilidad de disuasión y la mediación de un tercero como imparcialidad entre las partes conflictivas. Sobre estas técnicas se articulan acciones que no se consideran coactivas, sino "proactivas", destacándose su carácter de productoras de conductas.

En esta línea, la GU se propone como cuerpo "desarmado y de carácter eminentemente preventivo" que se pretende como ruptura respecto de la herencia de desprestigio de las fuerzas de seguridad tradicionales. En esta línea, se retoman los principios que definen la intervención de la Policía Comunitaria, para hacerlos extensivos a la GU: prevención y disuasión, diagnóstico local y comunitario, acciones proactivas y no coactivas, no basadas en el uso de la fuerza, evaluación y control ciudadano. Se trata de una intervención que se distancia de la represión para instalarse en el ámbito de la "promoción de conductas". Así, la GU aparece como cuerpo limpio e inmaculado. Y más allá de los logros efectivos, de la transformación o no de la conducta efectivamente lograda, destacamos que es de esta manera como se define y se piensa esta intervención.

Se trata de una presencia que es "presencia del Estado de la Ciudad en la calle” y que, por otra parte, pretende ser una presencia "amigable" para los ciudadanos (una vez más la distancia mencionada respecto de las fuerzas de seguridad tradicionales). Este distanciamiento respecto de las fuerzas tradicionales de seguridad que se asienta sobre todo en el descentramiento respecto del uso de la fuerza como medio de la intervención le permite despegarse de las críticas asociadas a las denuncias de "excesos" y "abusos" de la fuerza de que son objeto las fuerzas de seguridad tradicionales.

c. La apelación a los expertos A diferencia de otros personajes especializados paradigmáticos, ${ }^{22}$ el experto funda su legitimidad en una capacidad técnica de dar respuestas a urgencias instrumentales, lo que asegura la concreción de los valores de eficacia y eficiencia. En relación a la problemática específica de la seguridad, el experto se presenta como un sujeto de un saber sobre lo policial y la seguridad que desafía la exclusividad de la agencia policial respecto de este saber (Galeano, 2005; Kaminsky; Galeano, 2008).

Los proyectos que describen y adscriben al modelo de policía comunitaria retoman, en sus fundamentos, una serie de trabajos académicos referidos al tema. ${ }^{23}$ Se interpela a determinados actores de la esfera académica en tanto que expertos, es decir, portadores de un saber específico sobre la cuestión. Se trata de la apelación

${ }^{22}$ Un conjunto de personajes especializados en la creación, distribución y aplicación del saber a las cuestiones de políticas [...] Se trata de unas figuras que desempeñan roles muy diferentes tanto de los del prototípico "intelectual" o el "científico' de la era liberal como de los del "técnico” o "ingeniero social” de la era keynesiana (de Marinis, 2004, p. 79).

${ }^{23}$ Así, por ejemplo, alusiones al "doctor Jack R Greene, catedrático de justicia penal y director del Centro de Política Pública de la Universidad Temple de Filadelfia” y al "profesor estadounidense Herman Goldstein" (Proyecto de Ley n²004-1484, "Policía Metropolitana”, presentado por el bloque Frente para la Victoria), "los trabajos pioneros de Albert Reiss, Herman Golsdtein, Wilson y Kelling” (Proyecto de Ley $n^{\circ}$ 2004-1767, Policía Comunitaria, presentado por el bloque Compromiso para el Cambio); así como apelaciones a trabajos latinoamericanos como los del "catedrático de la Universidad de Chile Hugo Frühling", y "Marcelo Amodio miembro del Consejo Académico de la facultad de Derecho de la UNLP“ (Proyecto de Ley 2004-1484). 
a un sujeto supuesto saber (Lacan, 2003) ${ }^{24}$ que da cuenta de una relación de fuerzas que se establece respecto a lo que se puede llamar el problema de la seguridad. Lo que parece puesto en cuestión es la exclusividad de la agencia policial en relación a la producción de saber sobre aquello que hay que gobernar. Desde el momento en que una pluralidad de voces y espacios son habilitados como palabra seria y espacio legítimo, desde entonces el saber sobre qué hacer no es un saber exclusivamente policial. Se apela a la voz de los expertos para fundamentar, justificar, legitimar la política pública en cuestión. En este caso, un modelo y diseño institucional para la policía de la ciudad.

Los expertos tematizan el "agotamiento" del modelo de policía tradicional, y en relación a este agotamiento proponen un nuevo modelo. Entre otras cosas, la preocupación pasa por restablecer la legitimidad de la fuerza policial frente a los "ciudadanos". Para ello, no sólo se renuevan los fundamentos discursivos y la retórica de legitimación, sino que se proponen prácticas de "acercamiento" de la institución a los ciudadanos. Se trata de influir en la percepción que se tiene de la policía y los cuerpos de seguridad, pero también de establecer mecanismos para promover prácticas orientadas a ese "acercamiento". En esta línea se inscriben todas las propuestas "participativas" que se proponen componer la relación de la institución policial con la comunidad o la ciudadanía. Lo que se plantea como objetivo es reparar la confianza de la segunda en la primera, y, para ello, es estratégico lo que podríamos llamar como cierto "transparentamiento" de la institución, retomando lo que aparece como pretensiones de transparencia y control democrático de su funcionamiento. Es en función de este transparentamiento que la apelación a los expertos también resulta estratégica, no sólo en tanto que actores legitimados, portadores de un saber válido, sino en tanto se reconocen a sí

${ }^{24}$ La fuerza de la frase se juega en la reversibilidad y la ambigüedad de la relación entre los términos: se supone un saber, se supone un sujeto, se le supone un saber a un sujeto, se le supone un sujeto a un saber... mismos como ciudadanos y, de esta manera, esta relación de lo político y lo académico se vuelve una de las formas de la proximidad deseada.

En esta revisión de la disputa por el ejercicio del poder de policía, que se construye en los términos de una contraposición - modelos alternativos (policía comunitaria y de proximidad) vs. modelo tradicional (al que quedan asociadas la Policía Federal Argentina y la Policía de la Provincia de Buenos Aires) -, hemos identificado tres ejes: la reivindicación de lo local como nivel de pertinencia del gobierno; el cuestionamiento del uso de la fuerza; y la apelación a una expertise. Al desglosar la trama en que se articulan es que hemos podido hacer emerger una serie de elementos que se anudan y refuerzan mutuamente: eficacia y eficiencia, gobierno local, proximidad, transparencia, participación. Son las marcas que se inscriben en esta disputa como huellas de otro problema. Ese otro problema, que remite a otro nivel de generalidad, es el de la redefinición de las relaciones de gobierno y la manera en que se reflexiona acerca de ellas. Son elementos que muestran los términos que se redefinen tanto lo que debe ser el "buen gobierno", como los mecanismos adecuados de su producción (inter allia el poder de policía). A continuación, nos detendremos en cómo se redefine lo que constituye su objeto: la seguridad.

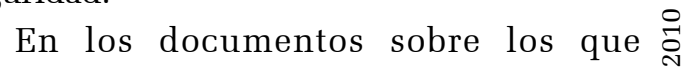
trabajamos, la seguridad es definida como deber irrenunciable de Estado, como algo que el Estado tiene la obligación de "ofrecer" a todos los habitantes. Y, al mismo tiempo, la seguridad es pensada como un derecho de todo ciudadano. Primer registro, entonces: el de los derechos y deberes del Estado y del ciudadano. La seguridad es un bien que hay que producir, y el Estado tiene una responsabilidad primaria en esa producción: debe intervenir para hacer.

La seguridad es aprehendida en los términos de un esquema del tipo "problema-solución", respecto del cual ésta es apreciada como un doble problema. Se trata de un desdoblamiento que se ordena en torno a una serie de pares de alterna-

$\frac{1}{2}$


tivas, pares de elementos no opuestos, sino complementarios. Se trata de una dualidad que se inscribe en diferentes registros:

\begin{tabular}{|r|l|}
\hline Delito violento & Pequeñas incivilidades \\
\hline Incremento de los niveles de violencia & Problemas de convivencia \\
\hline Inseguridad objetiva & Sensación de inseguridad \\
\hline
\end{tabular}

Este doblez del problema aparece claramente expresado en el Proyecto de Creación de la Guardia Urbana. Allí también se explicita algo que, a primera vista, podría resultar llamativo. Es el hecho de que se considera que aunque esta serie de pares también puede formularse en términos jurídicos a partir de la dupla contravención - delito, no obstante ello, se señala la insuficiencia de las categorías jurídicas para abordar el problema de la seguridad. ¿En qué radica esta insuficiencia? Por un lado, en la naturaleza que se atribuye a aquello sobre lo que se quiere intervenir: la experiencia de la (in)seguridad. La (in)seguridad como experiencia es una forma de vivir, y en tanto tal escapa siempre a las categorías jurídicas. Pero, por otro lado, esta insuficiencia de las categorías jurídicas habla también del tipo de efectos que se quieren suscitar.

El sujeto del que habláramos es el nudo de la cuestión. Por un lado, porque la intervención gubernamental busca afectar unas determinadas conductas. Sea previniendo su ocurrencia, es decir, multiplicando los mecanismos para evitar que tenga lugar, esto para el caso de las conductas transgresoras o conflictivas; sea promoviendo conductas que se consideran deseables para la buena “convivencia de los ciudadanos". Pero, más allá de este nivel más directo, se plantea otro nivel de incidencia de la intervención, y que está ligado a la "dimensión subjetiva del problema de la seguridad". Desde esta perspectiva, la generación de conflicto de temor compromete la producción de subjetividad y de pautas de relación entre los sujetos. Es decir que la producción de sujetos inseguros también es un problema para el gobierno, porque son sujetos que en tanto se sienten enfrentados a un riesgo y tienen miedo, generan pautas de interacción que refuerzan esa (in)seguridad, por ejemplo en lo que refiere a hábitos relativos al uso de los espacios. La sensación de inseguridad aparece en la génesis de una mayor inseguridad. En este sentido, podemos señalar, por ejemplo, la preocupación por "el abandono del espacio público" por parte de los "vecinos" y por las variadas formas de intervención que se proponen revertir estas prácticas, formas que se articulan en lo que se llama "recuperación del espacio público" (cercado de plazas, relocalización de ferias, incluso la iluminación de calles, todas formas de regular los usos de los espacios públicos y la manera de estar en ellos). De ahí el interés en este desdoblamiento de la seguridad en seguridad objetiva y sensación de inseguridad, y la posibilidad de intervenir en uno u otro nivel o incluso en ambos. Entones, por esta vía de afectar la conducta de los hombres, se busca incidir incluso, y en último término, en la experiencia de subjetivación de dicho sujeto y en la forma en que esta experiencia se despliega como elemento estructurante de las relaciones sociales.

\section{La Guardia Urbana como una solución de compromiso}

Hasta agosto de 2007, la Ley Cafiero limita la capacidad política de la Ciudad respecto de la creación de una fuerza de seguridad propia, supeditándola a una autorización expresa del Congreso Nacional. Durante el año 2004, el entonces jefe de gobierno de la Ciudad, Aníbal Ibarra, y el oficialismo en su conjunto, por medio de sus representantes en la Legislatura, demandan, ante las autoridades nacionales, la reforma del este artículo $7^{\circ}$ de la ley Cafiero, mediante actuaciones formales e incluso canalizando estas demandas a través de los medios de comunicación. Pues mientras no se reforme esta ley, legalmente no hay posibilidad de policía de la Ciudad o cuerpo de seguridad alguno sin autorización del Congreso de la Nación. 
Ahora bien, con la mirada puesta en el mediano plazo, y con vistas a la construcción política de una negociación y un consenso para la reforma de la Ley Cafiero, la Legislatura de la Ciudad trabaja con proyectos de creación de una policía dependiente administrativa y políticamente de la Jefatura de Gobierno de la Ciudad de Buenos Aires. Se trata de proyectos que comparten el carácter indiscutible de cuerpos de seguridad, y conllevan, de manera implícita o explícita, dos cuestiones: en primer lugar, la reforma de la ley Cafiero, pero también la discusión acerca de la transferencia de recursos del Estado Nacional hacia el Gobierno de la Ciudad. En cambio, la estrategia del poder ejecutivo de la Ciudad se orienta a encontrar una alternativa en el corto plazo. Dados los fracasos de la negociación por la reforma de la Ley Cafiero, se propone una alternativa que, entre las pretensiones de autonomía respecto del gobierno de la seguridad y las prerrogativas que mantiene el gobierno nacional en el ámbito de la ciudad, se presenta como solución de compromiso que satisface ambas exigencias. Es en este contexto que se empieza a elaborar el proyecto de creación de la Guardia Urbana. Estratégicamente, el ejecutivo porteño no plantea directamente la creación de un cuerpo de seguridad sino por vía de una reforma en la estructura administrativa de las dependencias del Gobierno de la Ciudad de Buenos Aires. Tal como hemos mencionado, el 22 de noviembre de 2004, el entonces jefe de gobierno de la Ciudad Autónoma de Buenos Aires (CABA) suscribe el decreto mediante el cual se da lugar a la creación de la Dirección General de Guardia Urbana, dependiente de la Subsecretaría de Seguridad Urbana de la Secretaría de Justicia y Seguridad Urbana. ${ }^{25} \mathrm{El}$ decreto, literalmente hablando, no crea un cuerpo de seguridad, sino la Dirección de Guardia Urbana, dependiente de la Secretaría de Seguridad, pues la creación lisa y llana de un

\footnotetext{
${ }^{25}$ Se trata del Decreto $n^{\circ} 2124 / 04$, publicado en el Boletín Oficial de la Ciudad de Buenos Aires n ${ }^{\circ} 2074$, disponible en: www.buenosaires.gov.ar/areas/leg_tecnica/boletines/ 20041124.htm (Ver Anexo 2).
}

Cuerpo de Seguridad requeriría la aprobación del Congreso de la Nación. Aparece más bien como una mera reforma administrativa institucional. ${ }^{26}$

De esta manera, se sortean los obstáculos legales que impedían al Gobierno de la Ciudad de Buenos Aires implementar una herramienta de intervención sobre lo que define como el problema de la (in)seguridad. Lo hace creando un cuerpo de seguridad que no aparece directamente definido como tal. Ambigüedad que constituye su condición de posibilidad, pero que, más adelante, se hará notar como su debilidad intrínseca, al no poder asumir las demandas de orden y de "más policía" que crecientemente empezarán a hegemonizar las discusiones acerca de la (in)seguridad.

Pero, ¿qué es este Cuerpo de Guardia Urbana? Aquí ensayamos una presentación de las competencias de actuación y las funciones específicas que se prevén para este nuevo dispositivo. Al respecto, el mismo decreto establece que se trata de un cuerpo de agentes que "tendrá como objetivos principales desarrollar acciones de prevención, disuasión, persuasión y mediación ante la ocurrencia de conflictos y eventuales transgresiones en el espacio público; así como actuar en la asistencia y orientación del ciudadano ante situaciones de riesgo y (o) emergencia en la vía pública”.

En primer lugar, cabe destacar que lo que se establece como el ámbito de intervención es definido en términos de "lo público", a saber:

${ }^{26}$ Artículo $1^{\circ}$ - Créase la Dirección General Guardia Urbana de la Ciudad Autónoma de Buenos Aires, dependiente de la Subsecretaría de Seguridad Urbana de la Secretaría de Justicia y Seguridad Urbana, y su instancia adjunta, asignándoseles Función Crítica Alta de conformidad con lo previsto en los artículos $5^{\circ}$ y 10 del Decreto $n^{\circ} 726 /$ GCBA/2001 y su modificatorio $n^{\circ} 761 /$ GCBA/2001, siendo sus Responsabilidades Primarias las consignadas en el Anexo I, el que a todos sus efectos, forma parte integrante del presente.Artículo $2^{\circ}$ - Suprímase la Dirección General Adjunta Cuerpo de Emergencias en la Vía Pública (C.E.V.I.P.), transfiriéndose todo su personal, patrimonio y presupuesto a la Dirección General Guardia Urbana de la Ciudad Autónoma de Buenos Aires. Artículo $3^{\circ}$ - Créase el Cuerpo Guardia Urbana, con dependencia directa de la Dirección General Guardia Urbana, cuyas funciones y objetivos se definen en el Anexo II del presente Decreto. [Decreto $\mathrm{n}^{\circ} 2124 / 04$ del Poder Ejecutivo de la Ciudad de Buenos Aires, publicado en el BOCBA n $\left.{ }^{\circ} 2074\right]$

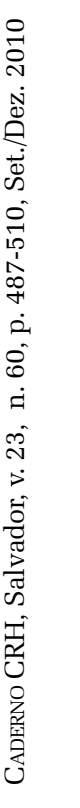


vía pública, espacios públicos, espacios verdes, corredores turísticos e inmediaciones de establecimientos educativos. Este es el espacio en el que debe desenvolverse una presencia del Estado, presencia del Estado en su nivel más local: presencia del Estado de la Ciudad.

Por otra parte, tratase de constituir una presencia del Estado de la Ciudad en la calle, que asume una funcionalidad específica relativa al problema de la seguridad. Es definido como un "cuerpo de seguridad" que, sin embargo, no asume las características atribuidas a las fuerzas de seguridad tradicionales tales como la Policía Federal Argentina y la Policía de la Provincia de Buenos Aires, aunque sí se les reconoce parte de la funcionalidad a estas imputada (centraremos nuestra comparación sobre todo con la Policía Federal, porque es esta fuerza la que tiene jurisdicción sobre el mismo territorio en el que viene a desplegarse la Guardia Urbana). Un punto de diferenciación central lo constituye sin duda el lugar que ocupa el problema de la "comisión de delitos" en la organización de las fuerzas y sus intervenciones diarias. Es ésta una cuestión central para la Policía Federal en territorio de la Ciudad de Buenos Aires, con competencias de policía judicial incluso. Mientras que, por el contrario, según claramente lo establecen las funciones atribuidas a la Guardia Urbana, ésta sólo interviene para "dar inmediato aviso a la autoridad competente y (o) requerir el auxilio de la fuerza de seguridad".

La Guardia Urbana se plantea como una tecnología híbrida: un mecanismo que se define como diferente de una fuerza de seguridad tradicional, pero que, no obstante, pretende dar respuesta al problema de la (in)seguridad. La Guardia Urbana, al mismo tiempo, es y no es una fuerza de seguridad. Es decir, si bien se pretende que la Guardia Urbana sea un cuerpo específico y capacitado en materia de seguridad, no se la termina de definir como una "fuerza de seguridad", en tanto las mismas han sido asociadas a la particular competencia de intervenir ante la comisión de hechos delictivos, situaciones frente a las cuales la Guardia Urbana no hace otra cosa que habilitar los medios para dar intervención a la fuerza de seguridad competente. En este sentido, la Guardia Urbana no es una fuerza de seguridad. No obstante ello, se declara su capacidad de contribuir al ejercicio del poder de policía, esto en la medida en que, por ejemplo, "corresponde dotar a los agentes integrantes de este nuevo Cuerpo de la facultad de labrar actas ante aquellas conductas que configuren una falta y (o) efectuar decomisos cuando correspondiere." y que dichos agentes colaborarán "en los operativos de verificación y control que requieran de un abordaje integral de poder de policía que ejerce el Gobierno de la Ciudad Autónoma de Buenos Aires". (Fuente: Decreto de Creación de la GU).

De lo anterior, nos interesa destacar dos cosas. En primer lugar, de estos documentos considerados podemos extraer una concepción de lo policial que excede la función de persecución o prevención del delito. El poder de policía aparece asociado a la producción de regulaciones, controles, ordenamientos, vigilancias. En definitiva, ligado a la cuestión más amplia del gobierno municipal, y de la Guardia Urbana como la fuerza auxiliar con la que debe contar cualquier gobierno para ser un gobierno efectivo, es decir, para efectivamente conducir las conductas. En segundo lugar, que también el problema de la seguridad se plantea como excediendo el de la delincuencia. La seguridad, en tanto problema de gobierno, comprende: el desorden en el tránsito y la (in)seguridad vial (en relación a ello también la circulación peatonal); los problemas de convivencia entre los distintos actores que viven en la ciudad (la conflictividad urbana), entre los que se incluyen, por ejemplo, conflictos relativos al uso de los espacios públicos, a las maneras de habitar la ciudad. En fin, tanto la seguridad como lo policial se definen en un sentido amplio, dos rasgos de la matriz en la que es posible la emergencia de la GU.

La relación entre la construcción del problema de la seguridad y la definición de la función policial está marcada por las correspondencias que se establecen entre la definición del problema y las posibles soluciones: de ahí el valor diferenci- 
al que cobran distintos elementos asociados a ciertas maneras de concebir la función policial (el uso de la fuerza, la "proximidad", etc.) respecto de formas diferentes de problematizar la cuestión de la seguridad.

Como describiéramos más arriba, la seguridad se construye como un problema doble. Ahora planteamos que, como doble es el problema, doble es la respuesta que se pretende adecuada. No se trata de la adscripción a uno u otro de los modelos de policiamiento señalados, sino la posibilidad de su integración lo que se formula como una respuesta adecuada. La emergencia de la Guardia Urbana, en este contexto, aparece como la encarnación de la posibilidad de un modelo dual, la compatibilización de lo nuevo y lo que existe. Dualidad que refiere tanto al modelo de policiamiento, la manera de ejercer el poder de policía, como a una forma de gobernar la ciudad, ambos en íntima relación.

Desde el punto de vista policial, la Guardia Urbana se presenta como el complemento de una Policía Federal desbordada por la multiplicidad de tareas y funciones que debe cubrir. Viene a sacar de la órbita de la Policía Federal Argentina un cúmulo de acciones, como, por ejemplo, aquellas vinculadas a la organización del tránsito, para que, de esta manera, la Policía Federal se pueda "concentrar" en aquello que debe ser prioritario, el delito. Esta concepción dual y complementaria de lo policial esgrimida por los funcionarios es recuperada en distintas notas periodísticas en los medios gráficos de comunicación masiva. Así, por ejemplo: "Además, 'su trabajo descomprimirá al de la Policía, que se podrá encargar más de combatir el delito en lugar de estar, por ejemplo, cuidando una plaza', aseguró el secretario porteño de Seguridad, Juan Carlos López" (Clarín, 02/11/2004).

En este sentido, se destaca la "integralidad" de la propuesta de creación de Guardia Urbana, integralidad que consiste justamente en "la integración con dispositivos ya existentes" para completar un esquema dual con la Policía Federal. Esquema dual que supone "dos dispositivos diferentes actuando conjuntamente" (Proyecto de creación de la Guardia Urbana, Secretaria de Justicia y Seguridad del GCBA, 2004). Su puesta en funcionamiento va a significar la articulación de un esquema dual para el ejercicio del poder de policía en la Ciudad de Buenos Aires. Es decir, lo que aparecía como la separación entre lo policial y la regulación municipal va ahora a reordenarse en torno a un desglose de las propias funciones policiales: por un lado, un poder de policía de carácter municipal, ligado a la función regulatoria, y que va a ser asumido por una Guardia Urbana (entran en esta órbita cuestiones tales como el ordenamiento del tránsito vehicular, control de habilitaciones y clausuras, etc.); por otro, las funciones mayores de orden y seguridad, control y presencia en manifestaciones y la represión del delito urbano.

Pero por otra parte, decíamos, esta dualidad no refiere exclusivamente al ejercicio del poder de policía, sino también, en sentido más amplio, a una forma de gobernar la ciudad. Esto en la medida en que la creación de la Guardia Urbana se presenta como una posible solución de compromiso entre los intereses nacionales y autonómicos. En este sentido, encarna un prototipo de fuerza de seguridad de la Ciudad, aun antes de la derogación del artículo $7^{\circ}$ de la Ley Cafiero, que se estructura como complemento de las fuerzas de seguridad dependientes del gobierno nacional. Pero más que la adaptación a un obstáculo normativo, constituye la encarnadura de una manera de gobernar la ciudad que se articula entorno de una relación nacional-local que podemos definir en términos de una autonomía posible. Lo que aparece presentado como novedad es que este complemento de la Policía Federal Argentina sea un cuerpo de agentes que dependen absolutamente, política y administrativamente, del poder ejecutivo de la Ciudad de Buenos Aires. En definitiva, lo que la Guardia Urbana viene a encarnar es la autonomía posible respecto del gobierno de la seguridad, y antesala de la autonomía pretendida.

$\mathrm{Al}$ recuperar esta contraposición de modelos de policiamiento, lo que quisimos marcar es que la emergencia de la GU es posible en par- 
te porque se da en un contexto en el que se valoran positivamente formas de policiamiento diferentes, con características distintivas que las distancian de las formas de policiamiento tradicionales en la que es inscripta la Policía Federal. La GU se presenta como encarnación de esos modelos de policiamiento alternativos a los tradicionales. Es decir, la GU emerge en esa brecha que se abre con la posibilidad de pensar lo policial de otro modo. Que tiene que ver con la posibilidad de pensar el problema de la seguridad en términos de "seguridad ciudadana".

\section{PUESTA EN FUNCIONAMIENTO}

\section{El proceso de conformación de la Guardia Ur- bana}

La Guardia Urbana de la Ciudad de Buenos Aires tiene su origen en la alteración de otras funciones e instancias municipales. Su composición inicial se realizó sobre la base del personal afectado al Cuerpo de Emergencias en la Vía Pública (CEVIP) cuya transferencia a la Dirección de Guardia Urbana (del personal afectado y todo su patrimonio) queda establecida en el mismo Decreto de su creación. Es así que, de los primeros 300 agentes que en junio de 2005 salen a las calles de la ciudad, 120 han sido trabajadores del CEVIP. La incorporación de los 180 trabajadores que completan el total de 300 guardias urbanos que inicialmente componen el cuerpo es el resultado de un proceso de convocatoria pública, selección y capacitación sobre el que nos detendremos más adelante (procesos que, como veremos, también rigieron las restantes incorporaciones de personal).

Luego del traspaso de los trabajadores del CEVIP y la incorporación inicial de 180 guardias, se llevan a cabo cuatro tandas de incorporaciones más. ${ }^{27}$ Cada una de estas tandas de incorporaciones

${ }^{27}$ En diciembre de 2007, antes de su disolución, el cuerpo de Guardia Urbana estaba conformado por 887 agentes. Nótese que el número de agentes refiere a la cantidad de "operativos", es decir, al personal que cumple funciones fue el resultado de un proceso de selección de personal e implicó la puesta en marcha de mecanismos de capacitación diseñados específicamente a los fines de la conformación de este cuerpo.

Los guardias urbanos que ingresan al cuerpo se incorporan en grupos de aproximadamente 20 integrantes, llamados "unidades". Las unidades están distribuidas en bases operativas, es decir, en centros de operaciones desde los que se imparte la logística de las intervenciones realizadas por las unidades. Estas bases operativas fueron primero tres, ubicadas en los barrios de Constitución, Villa Luro y Villa Crespo, a la que se sumó con posterioridad una cuarta en el barrio de Parque Chacabuco. Cada unidad de trabajo cuenta con un coordinador, que es el responsable, frente a sus superiores, del trabajo del grupo. Los coordinadores de unidad responden, a su vez, a un "coordinador de base", responsable de todas las unidades que tienen sede en la misma base de operaciones. A su vez, existe una coordinación operativa que centraliza la dimensión operativa del trabajo del cuerpo. Dimensión que se pone en paralelo con las de planeamiento y de administración (Gráfico 1).

Nos interesa detenernos en el carácter que podríamos llamar "arbóreo" de esta distribución. Y esto implica, en primer lugar, el carácter sumamente segmentado de la estratificación. Segmentación en sentido vertical, por supuesto, que es el sentido en que se transmite la función de coordinación. Pero, sobre todo, segmentación horizontal: al representarla gráficamente, la organización de la Guardia Urbana puede esquematizarse mediante una figura piramidal muy chata, amplia en la base, al nivel de las múltiples unidades. Esta base es la que se ensancha con la incorporación de nuevos agentes (y debe cubrir la superficie de la ciudad).

“en calle”. Las cifras y fechas fueron reconstruidas a partir de diversas fuentes: entrevistas a funcionarios, a guardias urbanos y a otros trabajadores afectados a tareas administrativas, informes de gestión de la página web oficial del Gobierno de la Ciudad de Buenos Aires y publicaciones de medios gráficos. Se trata siempre de referir la fecha de incorporación al trabajo en calle y no la el inicio del proceso de capacitación. 


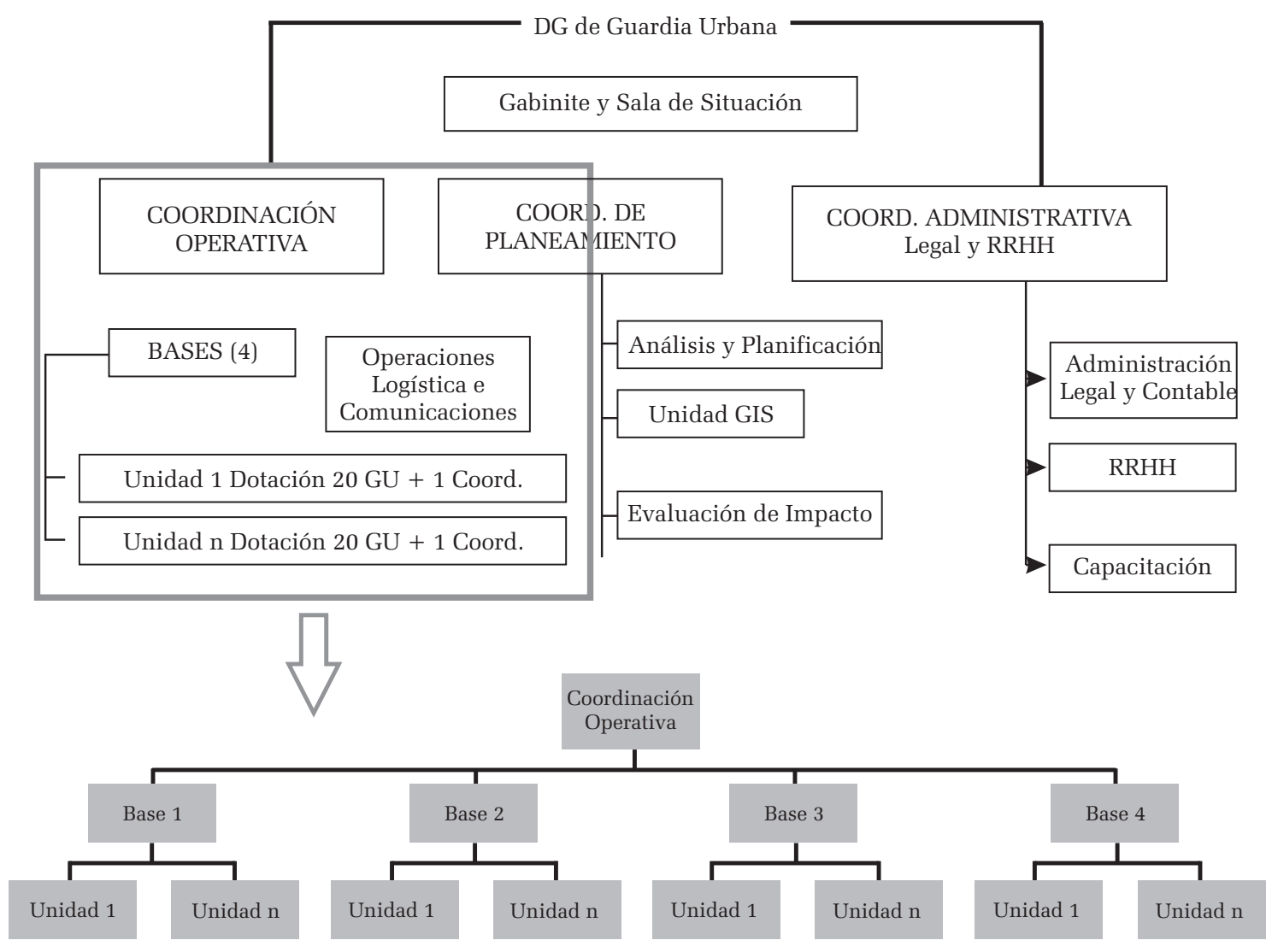

Fuente: Subsecretaría de Seguridad Urbana. GCBA

En segundo lugar, si bien es sumamente segmentada, se trata de una estratificación integrada. Esto también en dos sentidos. Por un lado, que no se abandona del todo la relación de verticalidad, y que esta verticalidad tiende a confluir en un único centro o eje; en este sentido se diferenciaría de una organización rizomática (Deleuze, 2002), descentrada, multicéntrica, reticular. Por otro, se trata de una estratificación integrada en el sentido de que, más allá de la distinción funcional entre personal "operativo" y personal "administrativo", no hay, en lo que respecta a los agentes, es decir, al personal operativo, otras diferenciaciones que lo fragmenten sustancialmente. Señalamos esto en contraste con la división del personal policial en oficiales u suboficiales que caracteriza a una fuerza como la Policía Federal Argentina, el "doble escalafón" a través del cual se reproduce una forma militar de ejercer el gobierno de la institución policial en nuestro país (Palmieri; Martínez; Sozzo; Thomas, 2001). En la Guardia Urbana, no hay doble escalafón. Incluso, la distinción de algunos de sus miembros con la función de coordinación no es una promoción propiamente dicha, en tanto no supone ni diferencia salarial ni un derecho adquirido; es una distinción funcional y provisoria, no implica una "carrera" ni diferencias de grado o escala. El lugar que ocupa cada agente no es un puesto en un escalafón. En lugar de este, hay una jerarquización no lineal y móvil.

Esta contraposición con el esquema organizacional de la Policía Federal Argentina nos pone frente al hecho de que la creación de la 
Guardia Urbana está acompañando el intento de creación de una Policía de la Ciudad de Buenos Aires ligada a modelos de policiamiento alternativos al que tradicionalmente encarnan las fuerzas de seguridad en nuestro país. Frente a la vigencia de la Ley Cafiero, ${ }^{28}$ la creación de dicha policía, en el ámbito del poder ejecutivo del Gobierno de la Ciudad de Buenos Aires, no es posible.

\section{La Guardia Urbana: "Una presencia que nos beneficia a todos"}

Desde su lanzamiento, la Guardia Urbana es promocionada como "una presencia que nos beneficia todos”. Esta presencia significa, en primer lugar, lisa y llanamente: estar en la calle. Lo que diferencia a este cuerpo de otros cuerpos municipales anteriormente existentes, como la Guardia de Auxililio o el CEVIP, es que la Guardia Urbana se plantea como una presencia permanente en el espacio público, y no sólo una presencia en la emergencia o a demanda. Es una presencia fácil de advertir, en la medida en que su uniforme los identifica: conjunto deportivo de color verde petróleo, atravesado por líneas horizontales de refracción lumínica en piernas y brazos, gorra visera, silbato, handy. Estos elementos constituían el equipo e indumentaria de un guardia urbano. Y es, por otra parte, una presencia que circula.

En principio, el personal de la Guardia Urbana no se ubica en una zona especial de la Ciudad, sino que rota por todos los barrios o por los lugares en los que se realicen operativos específicos. Circulación vehiculizada por 30 efectivos en bicicleta y 40 móviles (autos, camionetas y motos). Las "bases operativas", donde funcionan equipos de logística, coordinación y

${ }^{28}$ No es una mera cuestión legal. La vigencia de la Ley Cafiero y el problema de una "policía propia" y de la transferencia de la Policía Federal Argentina a la Ciudad nos remite a un complejo entramado de relaciones de fuerza a nivel nacional, que pone en juego el interés de las provincias y la cuestión de la coparticipación (al respecto puede verse el debate desarrollado en ocasión de la reforma de dicha ley así como los intereses del gobierno nacional en la ciudad.

de administración, son sólo los puntos de partida de los trabajadores que, desde allí, parten para realizar los recorridos planificados.

Y esta presencia es la presencia del Estado local en la calle. Así, cuando, en el año 2004, se comunica la creación de la Guardia Urbana, las palabras de Aníbal Ibarra, entonces jefe de gobierno de la Ciudad, anuncian una nueva "presencia de los ojos del Estado en la calle”. ¿Por qué el Estado (y no el Estado Nacional, sino el Estado de la Ciudad) necesita más ojos en la calle? ¿Qué miran esos ojos, qué ven? Detrás de esta iniciativa del Gobierno de la Ciudad de Buenos Aires vemos una concepción de Estado Nacional que, como totalidad, sólo puede ser legítimo si reconoce la autonomía de las partes que lo constituyen, la autonomía local. Estado Nacional como totalidad descentrada: un descentramiento que reivindica los niveles locales de gobierno en relación a la posibilidad de intervenciones eficaces respecto de los temas que se elaboran como problema, principalmente la seguridad.

\begin{abstract}
Damos por supuesto que el espacio público es el lugar de ocurrencia principal, de mayor conflictividad y de mayor responsabilidad para el Estado a la hora de responder en la preservación de la seguridad humana. [Proyecto de creación de la Guardia Urbana, Secretaria de Justicia y Seguridad del GCBA, 2004]
\end{abstract}

Para que sea posible el gobierno de manera efectiva, es preciso que tenga una presencia en ese afuera que es lo público. El cuerpo de Guardia Urbana es la materialización de esa presencia del Estado en el espacio público, es el cuerpo del Estado para el buen gobierno de lo público. Pero debe ser un cuerpo que deje ver el alma, es decir, la forma que asuma dicho cuerpo debe expresar y ajustarse al espíritu del gobierno: autónomo y democrático, eficaz, ágil, receptivo, joven. Lo cual remite, una vez más, al distanciamiento respecto de las fuerzas de seguridad tradicionales, asociadas al verticalismo y al autoritarismo y, subsecuentemente, a una forma de entender lo que debe ser el Estado, también diferente.

Se trata de una presencia del Estado de la 
Ciudad, que, a diferencia de la presencia del Estado nacional - que es una presencia para las autoridades nacionales para garantizar la paz de su residencia y para el orden -, debe ser una presencia para sus ciudadanos o "vecinos". Por ello, pretende ser una presencia "amigable" para los ciudadanos, que viene a prestarles un servicio: colaborar, prevenir, orientar. Estar cerca. Pretende ser una compañía: "Ya no estás sólo en la ciudad", canta la publicidad televisiva, mientras muestra la imagen de una joven atemorizada recorriendo sola las calles de un barrio porteño. ${ }^{29}$

Es una presencia que debe mostrarse, porque su efecto está precisamente en su visibilidad y no es la sospecha o el acecho de una mirada oculta e invisible. Por ello, para los guardias urbanos, las indicaciones no son sólo acerca de dónde estar, sino incluso cómo: no se pueden usar accesorios de vestimenta más allá de los reglamentarios, aún en invierno, no se puede llevar bufanda, guantes, las manos fuera de los bolsillos, la ropa en condiciones. En definitiva, asegurar una "buena presencia". ${ }^{30}$

No se trata de una presencia pasiva, sino que debe ser una presencia ordenadora. Debe, por ejemplo, ordenar la circulación peatonal: debe procurar que los peatones crucen por la senda peatonal y sólo bajen a la calle cuando el semáforo corta el tránsito vehicular. También prevenir situaciones conflictivas: interviniendo en peleas en el espacio público, sobre todo en relación a la realización de eventos masivos y espectáculos públicos. Presencia asociada, entonces, a la disuasión o prevención de conductas "conflictivas". La presencia en los llamados "Circuitos turísticos" refuerza un componente, el de brindar información y orientación al turista o ciudadano. Esta tarea es asumida por unidades de Guardia Urbana cuyos

${ }^{29}$ Publicidad emitida por la televisión abierta al momento de lanzamiento de la Guardia Urbana.

${ }^{30}$ De lo referido por los guardias urbanos entrevistados, hemos podido advertir que las reprimendas y sanciones están, en la mayoría de los casos, motivadas por "inconductas" de los guardias que van en esta dirección, referente a la vestimenta o a la actitud (tener las manos en los bolsillos, fumar o beber alcohol con el uniforme, etc). miembros poseen conocimiento de idiomas (inglés sobre todo).

\section{Guardia Urbana y Policía Federal Argentina: dos dispositivos diferentes actuando complementariamente}

Como decíamos, Aníbal Ibarra señaló que la creación de la Guardia fue una decisión tomada para fortalecer la presencia del Estado en la vía pública:

Todos sabemos que la Ciudad no cuenta con policía propia y este cuerpo no viene ni a reemplazarla ni a competir, sino que va a cumplir con funciones distintas, complementarias no sólo de las tareas que realiza la policía en la Ciudad de Buenos Aires sino también de otros organismos y cuerpos, muchos de ellos dependientes del propio Estado porteño", afirmó Ibarra. ${ }^{31}$

Con la creación de la Guardia Urbana, se busca fortalecer el desarrollo de las áreas de gobierno ya existentes en el Gobierno de la Ciudad de Buenos Aires, vinculadas a la seguridad, como la Secretaría de Justicia y Seguridad Urbana. Se planifica un aumento significativo del presupuesto asignado a estas dependencias. Pero esto, se insiste, no viene a reemplazar a la Policía Federal Argentina. Por el contrario este fortalecimiento del nivel de gobierno local se piensa a partir del reforzamiento de los vínculos con el gobierno nacional en lo que atañe a las formas de intervención que se habilitan en torno al problema de la seguridad. Estas vinculaciones se materializan en convenios, acuerdos y formas institucionales que también se buscan robustecer. Así es el acuerdo entre el Ministerio del Interior - Secretaria de Seguridad Interior - para constituir un gabinete conjunto en materia de política criminal; la formalización del flujo de información de estadística policial para

${ }^{31}$ Noticia publicada en el portal web del Gobierno de la ciudad de Buenos Aires: "Se puso en marcha la Guardia Urbana de la Ciudad de Buenos Aires”, publicada el 13 de junio de 2005. Disponible en: www.buenosaires.gov.ar/ noticias/?modulo = ver\&item id=18256\&contenido id $=3657$ \&idioma =es. Fecha de a cceso: 09 dic. 2007. 
el mapa del delito (SURC); y la formalización de instancias de coordinación institucional con la Policía Federal como podría ser el Comité Técnico, todas éstas iniciativas contenidas en el "Convenio de Policía Comunitaria". ${ }^{32}$

Este convenio fue suscripto en enero de 2004, por Gustavo Béliz, entonces Ministro de Justicia, Seguridad y Derechos Humanos de la Nación, y Aníbal Ibarra, titular del Gobierno de la Ciudad de Buenos Aires, y su principal interés es definir aspectos relativos a la prestación de servicios de la Policía Federal Argentina en el ámbito de esta ciudad. Este convenio se presenta como un acuerdo de trabajo conjunto: ${ }^{33}$

...con el objeto de establecer organismos responsables de coordinar estudios, realizar análisis y diseñar acciones conjuntas para la ejecución de políticas preventivas en materia de seguridad ciudadana, vinculadas a la prevención del delito y mantenimiento de la seguridad pública para la Ciudad de Buenos Aires.

Allí se define explícitamente las funciones de la Dirección General de Policía Comunitaria: prestará el auxilio de la fuerza pública a los funcionarios del Gobierno de la Ciudad de Buenos Aires, actuará como auxiliar del Poder Judicial y del Ministerio Público de dicha jurisdicción, sin perjuicio de la competencia que corresponde por Ley Orgánica a otras dependencias de la Policía Federal Argentina y coordinará los servicios que requieran el apoyo de otras áreas de la Policía Federal Argentina. El Comité Técnico de Seguridad Ciudadana es la instancia que se prevé garantizará la acción coordinada de las partes y la integración de sus intereses y necesidades. El funcionamiento de la Guardia Urbana pretende reforzar este esquema

${ }^{32}$ Este Convenio es aprobado por la Legislatura de la Ciudad de Buenos Aires con la sanción de la Ley 1931, publicada en el BOCBA n ${ }^{\circ} 2452$ del 05/06/2006.

${ }^{33}$ Este Acuerdo establece, en su cláusula primera, que: El MJSDH, a través de la Policia Federal Argentina (PFA), creará la Dirección General de Policia Comunitaria en el ámbito de la Superintendencia de Seguridad Metropolitana, con la misión de concentrar, analizar coordinar e instrumentar programas de seguridad ciudadana que se establezcan consensuadamente entre LAS PARTES en materia contravencional, tránsito, seguridad en parques, plazas, espacios verdes u otros lugares que se determinen y en todas aquellas acciones y programas que resulten de la ejecución del Plan de Prevención del Delito. integrado. Así lo muestra lo que se organiza como "Matriz de Actuación Intervención Guardia Urbana/Policía Comunitaria" (Tabla 1), la cual:

...nos permite definir con mayor precisión las funciones y competencias que deberían tener los dos dispositivos, dando cuenta además de la complementariedad necesaria en muchos casos, la articulación y derivación adecuada en otros, y las secuencias de tiempo y diferencias de modalidad en la intervención que es necesario establecer. Así mismo reafirma la necesidad de fortalecer un organismo de diseño, planificación, supervisión, control de ejecución y relación con la comunidad como lo es el Plan de Prevención del Delito en la actualidad. Uno de los pilares para obtener un buen resultado en la implementación de estas políticas es la especialización y perfeccionamiento de la coordinación, planificación, diseño, diagnóstico, evaluación y análisis a través de una instancia adecuada.

Según lo refieren los funcionarios responsables, esta matriz es construida sobre el tipo de incidentes más comunes que se producen en la Ciudad de Buenos Aires, definidos sobre la base del análisis sistemático de la experiencia desarrollada por el Plan de Prevención del Delito. Lo que queda plasmado en este diagrama es el punto en que la Guardia Urbana y la Policía Federal aparecen definidas como dispositivos complementarios, que no se yuxtaponen, sino que se distribuyen en relación a una pauta de partición que es, a su vez, matriz de la constitución de un problema: la seguridad.

La seguridad concebida como un problema dual, atravesado por una distinción fundamental entre delito contra la propiedad y la integridad física, por un lado, y las "pequeñas pero no menos conflictivas incivilidades" ${ }^{34}$, por el otro. Dos vertientes que hay que abordar de manera diferencial, y en esto radica la especificidad de la Guardia Urbana y sus formas de intervención: promoción, prevención, disuasión, resolución alternativa de conflicto. La intervención represiva queda reservada como potestad de la Policía Federal Argentina. De acuerdo a esta partición, el trabajo de la Guardia Urbana,

${ }^{34}$ Fuente: Proyecto de creación de la Guardia Urbana, Se-
cretaria de Justicia y Seguridad del Gobierno de la Ciudad de Buenos Aires, 2004. 
Tabla 1 - Matríz de Actuación Intervención Guardia Urbana - Policía Comunitaria

\begin{tabular}{|c|c|c|c|c|c|c|}
\hline Incidente, evento & $\begin{array}{l}\text { Modalidad de } \\
\text { Intervención } \\
\text { Nivel } 1\end{array}$ & RESP & $\begin{array}{c}\text { Modalidad de } \\
\text { Intervención } \\
\text { Ni vel } 2\end{array}$ & RESP & $\begin{array}{c}\text { Modalidad de } \\
\text { Intervención } \\
\text { Nivel } 3\end{array}$ & $\operatorname{Resp}$ \\
\hline $\begin{array}{l}\text { Accidentado en via } \\
\text { pública }\end{array}$ & Derivación & $\begin{array}{c}\text { Guardia } \\
\text { Urbana } \\
\text { /POLCOM }\end{array}$ & $\begin{array}{c}\text { Acción } \\
\text { Asistencia }\end{array}$ & SAME & $\mathrm{x}$ & $\mathrm{x}$ \\
\hline $\begin{array}{l}\text { Delito en } \\
\text { flagrancia ( robos, } \\
\text { hurtos) }\end{array}$ & Derivación & $\begin{array}{l}\text { Guardia } \\
\text { Urbana }\end{array}$ & $\begin{array}{l}\text { Coación , uso } \\
\text { de la fuerza } \\
\text { pública }\end{array}$ & POLCOM & $\mathrm{x}$ & $\mathrm{x}$ \\
\hline $\begin{array}{l}\text { Dispos ición } \\
\text { irregular de } \\
\text { residuos(horario o } \\
\text { lugar) }\end{array}$ & Disuación & $\begin{array}{l}\text { Guardia } \\
\text { Urbana }\end{array}$ & $\begin{array}{l}\text { Coacción sin } \\
\text { uso de fuerza }\end{array}$ & $\begin{array}{l}\text { Guardia } \\
\text { Urbana }\end{array}$ & $\mathrm{x}$ & $\mathrm{x}$ \\
\hline $\begin{array}{l}\text { Recurrencia de } \\
\text { delitos contra la } \\
\text { propiedad (robo } \\
\text { en gene ral, robo } \\
\text { automotor, hurto) } \\
\text { x información o } \\
\text { reclamo vecinal }\end{array}$ & $\begin{array}{l}\text { Relevamient y } \\
\text { registro }\end{array}$ & $\begin{array}{l}\text { Guardia } \\
\text { Urbana }\end{array}$ & Prevención & POLCOM & $\mathrm{x}$ & $\mathrm{x}$ \\
\hline Ruidos molestos & Disuación & $\begin{array}{l}\text { Guardia } \\
\text { Urbana }\end{array}$ & Mediación & $\begin{array}{l}\text { Guardia } \\
\text { Urbana }\end{array}$ & $\begin{array}{c}\text { Coacción sin } \\
\text { uso de la } \\
\text { fuerza }\end{array}$ & $\begin{array}{l}\text { Guardia Urbana } \\
\text { POLCOM }\end{array}$ \\
\hline $\begin{array}{l}\text { Venta de alcohol } \\
\text { en comercios no } \\
\text { habilitados }\end{array}$ & $\begin{array}{l}\text { Relevamient y } \\
\text { Registro }\end{array}$ & $\begin{array}{l}\text { Guardia } \\
\text { Urbana }\end{array}$ & Derivación & $\begin{array}{l}\text { Gu ardia } \\
\text { Urbana }\end{array}$ & $\begin{array}{l}\text { Coacción sin } \\
\text { uso de la } \\
\text { fuerza }\end{array}$ & DGFyC $^{35}$, POLCOM \\
\hline $\begin{array}{l}\text { Actividad } \\
\text { permanente de } \\
\text { circuito turístico }\end{array}$ & $\begin{array}{l}\text { Información } \\
\text { Orientación }\end{array}$ & $\begin{array}{l}\text { Guardia } \\
\text { Urbana }\end{array}$ & Prevención & $\begin{array}{c}\text { Guardia } \\
\text { Urbana }\end{array}$ & Prevención & POLCOM \\
\hline Senderos seguros & Información & $\begin{array}{l}\text { Guardia } \\
\text { Urbana }\end{array}$ & Prevención & $\begin{array}{l}\text { Guardia } \\
\text { Urban a } \\
\end{array}$ & Prevención & POLCOM \\
\hline
\end{tabular}

Fuente: Subsecretaría de Seguridad Urbana. GCBA

su utilidad, es valorada en tanto "descomprimirá al de la Policía, que se podrá encargar más de combatir el delito en lugar de estar, por ejemplo, cuidando una plaza" (tal como aseguró el secretario porteño de Seguridad, Juan Carlos López) (Clarín, 2-11-04). Se trata de una partición que posibilita una distribución funcional. El hecho es que las intervenciones de la Guardia Urbana se plantean como complementarias al accionar de la Policía (la Policía Federal Argentina y su división de Policía Comunitaria).

\footnotetext{
${ }^{35}$ Dirección General de Faltas y Contravenciones de la Ciudad de Buenos Aires.
}

\section{CONCLUYENDO}

La emergencia de la Guardia Urbana es posible en el marco de una particular configuración que hemos identificado como Seguridad ciudadana, configuración de sentidos y prácticas que se organizan en torno a la preocupación por pensar el Orden en términos de democracia. La articulación del discurso de la Seguridad ciudadana, que se opone al de "seguridad nacional", está fundado en la asociación seguridad + democracia. Esta asociación se establece en contraposición a aquella otra que vincula la seguridad al problema del orden público y la doctrina de la seguridad 
nacional, y que está estrechamente ligada a las experiencias dictatoriales. En esta nueva configuración del problema de la seguridad, atravesada ahora por la pretensión democrática, es que deja de hablarse de la función policial como "fuerzas del orden", y aparece una nueva objetivación (también en el campo académico): las fuerzas de seguridad. Este desplazamiento comporta además una fuerte crítica de las policías tradicionales y el rol desempeñado por ellas históricamente. En este contexto, la Guardia Urbana tiene sentido, es una propuesta pensable, válida porque no es una policía en el sentido tradicional de la palabra.

En este marco, la seguridad se instala como un problema que debe ser objeto de gobierno, $\mathrm{y}$ el gobierno como una serie de prácticas que deben producir seguridad. Un gobierno que, para ser eficaz en esta producción, debe ser local y autónomo, y, a su vez, democrático (se trata de un gobierno que se piensa y se aplica dentro de estos parámetros de eficacia y eficiencia, y se objetiva a sí mismo en estos términos). Y en articulación con los valores democráticos reivindicados por el discurso de la Seguridad ciudadana frente a la "seguridad nacional", surge la necesidad de plantear un modelo de policiamiento alternativo a los tradicionales. La contraposición entre seguridad ciudadana y seguridad nacional asume, respecto de la definición del ejercicio del poder de policía, la forma de otra contraposición: por un lado, un modelo de policiamiento tradicional, asociado al verticalismo, la militarización, la represión, frente al cual se postula un modelo de policiamiento alternativo, basado en una tradición de policiamiento menos presente en nuestro país, y más asociado a países anglosajones, (el "modelo ingles”), modelo conocido como de policía comunitaria o de proximidad, de perfil democrático, horizontal. Este modelo de policiamiento, que se presenta como "novedoso", participa de las cualidades que, al mismo tiempo, definen el "buen gobierno" de las cosas: reivindicación del nivel de lo local, eficacia y eficiencia, transparencia.
Frente a las restricciones que expresa la Ley Cafiero respecto de la autonomía de la Ciudad, no hay posibilidad de una policía propia en términos estrictos. La Guardia Urbana será correlato de la autonomía posible. Su instalación va aparejada a la recuperación de una manera particular de plantear el problema de la (in)seguridad como un doble problema, que alude, al mismo tiempo, a las "pequeñas incivilidades” y al "delito violento". Doble problema que exige una doble solución, que va a encarnarse en la propuesta de un modelo de policiamiento dual, que articulará a la Guardia Urbana con la Policía Federal Argentina.

En esta dualidad en que se delinea el problema de la seguridad, es que se plantea la posibilidad de una Guardia Urbana como algo útil y necesario. La Guardia Urbana no es propiamente una policía, y, sin embargo, es pensada en relación al ejercicio del poder de policía: se ocupará de "lo menos importante" para que la policía pueda ocuparse del "verdadero delito". Esto le permite plantearse en una relación de complementariedad respecto de la Policía Federal Argentina. La Guardia Urbana viene a deslindar preocupaciones. Por otra parte, es por no ser una policía que podrá reforzar unos efectos de orden que la policía no había podido asegurar. Porque la policía (la Policía Federal), en la medida en que, por cuestionada (ligada a la connivencia con el delito organizado y la corrupción, el uso ilegítimo de la fuerza, etc.), se halla "distanciada" de la ciudadanía. Tal es el punto en que se inscriben los discursos que apuntan a la legitimación de un nuevo cuerpo, "próximo" a la ciudadanía, "amigable", transparente, local, autónomo, democrático. Todos estos rasgos, cualidades del "buen gobierno", deben tener su encarnadura tanto en las técnicas y procedimientos comprometidos en la conformación de la Guardia Urbana, como en aquellas que comprenden su intervención.

Esta ambivalencia, la de no ser una policía y sin embargo plantearse como ejercicio del poder de policía, ser y no ser una fuerza de seguridad, le permite jugar un rol estratégico cuando la 
problematización de la seguridad está fuertemente marcada por la necesidad de pensar el Orden en democracia: esta marca es la de la exclusión del orden público en tanto "orden para el Estado". El discurso de la Seguridad ciudadana reconcilia al "ciudadano" con el "Estado", haciendo de la seguridad, al mismo tiempo, el nombre del Orden, un derecho del ciudadano, y obligación y responsabilidad del Estado.

Ahora bien, si en el contexto de emergencia de la Guardia Urbana, la seguridad era apreciada como un doble problema, vemos que, por el contrario, en el momento de su disolución, el problema de la seguridad se reconfigura a partir de la borradura de todas las distinciones que parecían importantes (aunque se puede seguir hablando de inseguridad objetiva e inseguridad subjetiva, por ejemplo, ahora se entiende que estas no son, "en esencia", cosas diferentes). Y en un movimiento complementario a este repliegue del problema, vemos como se instala la necesidad de una policía (definida en los términos tradicionales) como la única respuesta acorde al problema de la (in)seguridad. Con esto queremos decir: la solución queda definida en términos exclusivamente represivos, ya no se trata de producir "buenas conductas" ciudadanas, de promover conductas respetuosas de la ley y de los otros, algo que está muy presente en el "espíritu” de la Guardia Urbana. Es decir, al mismo tiempo que lo que era definido como un doble problema se pliega sobre uno de sus bordes, paralelamente también se observa un movimiento similar respecto de lo que constituye su solución, la dualidad se disuelve resolviéndose por uno de sus polos.

Esta resignificación de la "seguridad" está ligada a una recuperación de la idea de orden. Noción que había sido desplazada en el discurso de la Seguridad ciudadana en el que emerge la Guardia Urbana, donde “orden” aparecía como palabra maldita, ligada a las fuerzas del orden, la represión, el terrorismo de Estado y experiencias dictatoriales. Pero ahora aparece como santo y seña de una reconfiguración que reposiciona, junto a la seguridad, los valores de ley y orden, como valores republicanos. Los elementos mencionados constituyen la condición de posibilidad de la puesta en crisis del modelo dual en que se articulaba la Guardia Urbana. Esta puesta en crisis consiste en la articulación de una matriz de sentido, la producción de una verdad: lo que se necesita, imperiosamente, es una policía.

En esta crisis del modelo dual se asentarán las críticas dirigidas hacia la Guardia Urbana, la cual empieza a ser considerada como gasto inútil e innecesario. La Guardia Urbana no es una policía, el mismo rasgo que encontramos en la posibilidad de su emergencia se constituyó motor de su disolución. La crisis del modelo dual no refiere a la desaparición de combinación de técnicas, sino a las formas en que se construye discursivamente la anulación de la necesidad de algo como la GU, es decir, al declive de esta dualidad en tanto paradigma que fundamenta o legitima el "adecuado" ejercicio del poder de policía, adecuación respecto de lo que se establece que es el "buen gobierno" de la seguridad. Ha quedado establecido que lo que se necesita es una policía en términos tradicionales, es decir, una institución estatal centralizada, capaz de hacer uso de la fuerza de manera legítima con fines de coerción y represión del delito. Una "policía propia" es la solución del problema de la (in)seguridad. Esto es lo que viene a encarnar la Policía Metropolitana.

(Recebido para publicação em junho de 2010) (Aceito em setembro de 2010)

\section{REFERENCIAS}

ARGÜELLO, J. Autonomía de la ciudad de Buenos Aires: aportes para la discusión sobre sus alcances constitucionales. La Ley, 1995A, Buenos Aires, 1995.

. Buenos Aires: autónoma y descentralizada. Buenos Aires: Editorial de Belgrano, 2001.

DE GEOVANNI, J. Algunos aspectos del proceso autonómico de la ciudad de Buenos Aires y la sanción por el Congreso de la ley de garantías. La Ley, Buenos Aires, Tomo E-699, 1995. 
DE MARINIS, P. In/seguridad/es sin sociedad/es: cinco dimensiones de la condición postsocial. In: I. M.; J. P. (Org.. La relación seguridad-inseguridad en centros urbanos de Europa y América Latina. Estrategias políticas, actores, perspectivas y resultados. Madrid: Dykinson; Instituto Internacional de Sociología Jurídica de Oñate, 2004.

DELEUZE, G. Mil mesetas. Capitalismo y esquizofrenia Valencia: Pre-Textosm, 2002.

Foucault, M. Omnes et singulatim": hacia una crítica de la razón política. En: La Piqueta, 1996. ¿Qué es la ilustración? Madrid:

FOUCAULT, M. Vigilar y castigar: nacimiento de la prisión. $30^{\mathrm{a}}$ ed. Trans. Garzón del Camino, México: Siglo Veintiuno Editores, [1976] 2000.

El sujeto y el poder". In: DREYFUS, H.; RABINOW P. Michel Foucault: más allá del estructuralismo y la hermenéutica. Buenos Aires: Ediciones Nueva Visión, 2001a.

L' intellectuel et les pouvoirs, $n^{\circ} 359$. In: Dits et écrit II. 1976-1988 Paris: Gallimard, 2001b. p.15661571.

Subjetivité et vérité, $\mathrm{n}^{0} 304$. In: Dits et écrit II. 1976-1988. Paris: Gallimard, 2001c. p.1032-1037.

Historia de la sexualidad 1: la voluntad de saber. México: Siglo veintiuno editores, [1967] 2002.

Naissance de la biopolitique. Cours au Collège de $\overline{\text { France }}$, 1978-1979. Paris: Gallimard-Seuil, 2004a.

Sécurité, territoire, population. Cours au Collège de France, 1977-1978. Paris: Gallimard-Seuil, 2004b.

GALEANO, D. La seguridad que se aconseja. Expertos y burócratas en tiempos post-correccionales. La Trama: revista Interdisplinaria de Mediación y Resolución de Conflictos, Buenos Aires, UBA, n.16, 2005.

GONZÁLEZ BERGÉS, P. El gobierno en cierne de la Ciudad de Buenos Aires. Foro Político, Buenos Aires, v.14. 1995.

JARQUE, C. M. Prefácio. In: FRÜHLING, H. (Org.), Calles más seguras. Estudios de policía comunitaria en América Latina. Buenos Aires: Banco Interamericano de Desarrollo, 2004. p.13-24

KAMINSKY, G.; GALEANO, D. Hacer saber: la entrada de la seguridad ciudadana en la formación universitaria argentina. In: A.A.V.V (Org.) Estado, democracia y seguridad ciudadana. Buenos Aires: PNUD, 2008.

KESSLER, G. Introducción. Seguridad y Ciudadanía. In (Org.) Seguridad y ciudadanía: nuevos paradigma y políticas públicas. Buenos Aires: Edhasa, 2009.

LACAN, J. Del sujeto al que se supone saber, de la primera díada, y del bien. In: EL SEMINARIO: los cuatro conceptos fundamentales del psicoanálisis, 11, 2003. Buenos Aires: Paidos, 2003. p.238-251.

. B. J. Nacimiento y desarrollo de la policía institucional. Nueva Doctrina Penal, 1996 ${ }^{\mathrm{a}}$, Buenos Aires, Ed. del Puerto, p.55-74, 1996.

MOUZO, K. GALVANI, M.; RIOS, A. Entre las denuncias y las reformas. El estudio de las fuerzas de seguridad en la Argentina. In: SOZZO, M. (Org.) Titulo provisorio: sociología del sistema penal. Buenos Aires, 2009. Prelo.

OFFE, C. La política social y la teoría del Estado. In KEANE, J. Contradicciones en el Estado de Bienestar. México: Alianza Editorial, 1990.

PALMIERI, G.; MARTÍNEZ, J.; SOZZO, M.; THOMAS, H. Mecanismos de control interno e iniciativas de reforma en las instituciones policiales Argentinas. Los casos de la Policía Federal Argentina, la Policía de la Provincia de Santa Fe y la Policía de la Provincia de Buenos Aires. In: FRÜHLING H. CANDINA, A. (Org.) Policía, sociedad y Estado: modernización y reforma policial en América del Sur. Santiago de Chile: Centro de Estudios para el Desarrollo, 2001.

RANGUGNI, V. Reforma del Estado y políticas de «control del delito» en la Argentina de los años 1990. In: PEGORARO, I. M. y. J. (Org.) La relación seguridad-inseguridad en centros urbanos de Europa y América Latina. Estrategias, políticas, actores, perspectivas y resultados. Oñati,ES: Instituto internacional de Sociología Jurídica de Oñati; Editorial Dykinson, 2004.

. Emergencia, modos de problematización y gobierno de la in/seguridad en la Argentina neoliberal. Delito sociedad: revista de Ciencias Sociales, Santa Fe, AR Ed.UNL, v.18, n.27, p.23-44, 2009.

RECASENS i BRUNET, A. Policía y control social: problemas de definición y definición jurídica y social. 1989. Tesis (Doctoral inédita) - Universidad de Barcelona, 1989.

SABSAY, D. A. La ciudad de Buenos Aires y la reforma constitucional. Alcance de la autonomía acordada, consecuencias institucionales. In: HERZER H. M. (Org Gobierno y descentralzación. Buenos Aires: Oficia de Publicaciones del CBC-UBA, 1996.

SENELLART, M. Situation des cours. En: FOUCAULT, M. Sécurité, territoire, population. Cours au Collège de France. 1977-1978 Paris: Gallimard-Seuil, 2004. p.379-411.

\section{FUENTES DOCUMENTALES}

\section{a. Documentos legislativos}

Proyectos de ley presentados por los diferentes bloques de la Legislatura de la Ciudad de Buenos Aires, que versan sobre la creación de Policías o cuerpos de seguridad dependientes administrativa y políticamente del poder ejecutivo de la ciudad autónoma de Buenos Aires (CABA). En total son siete proyectos:

00073-D-2004, presentado por el legislador Diego Busacca (Frente Compromiso para el Cambio): "Ley Orgánica de la Policía de la Ciudad Autónoma de Buenos Aires".

00665-D-2004, presentado por los legisladores Rebot, Polimeni y González (Frente Compromiso para el Cambio): "Cuerpo de Policía de Tránsito”.

- 00673-D-2004, presentado por los legisladores De Giovanni, Giorno, Onega, Pérez y Ameijeiras (Partido de la Ciudad): "Creación de la Policía de la Ciudad Autónoma de Buenos Aires".

- 01030-D-2004, presentado por el legislador Diego Santilli (Frente Compromiso para el Cambio): "Creación de la Policía Metropolitana".

01484-D-2004, presentado por la legisladora Silvia La Ruffa (Frente para la Victoria): "Créase la Policía Metropolitana para asumir funciones de prevención y seguridad de personas y bienes".

01767-D-2004, presentado por los legisladores Enríquez, Busacca, Ferrero, Farias Gómez, Majdalani, González, Borrelli, Bergenfeld y Godoy (Frente Compromiso para el Cambio): "Creación del Cuerpo de Policía Comunitaria de la Ciudad".

-02218-D-2004, presentado por el legislador Jorge Enríquez (Frente Compromiso para el Cambio): "Creación de la Policía de la ciudad y disposiciones generales".

. Ley 1931, en: Boletín Oficial de la Ciudad de Buenos Aires $n .^{\circ} 2452,5$ de junio 2006. Convenio de Policía comunitaria entre el Gobierno de la Ciudad de Buenos Aires y el Ministerio de Justicia de la Nación.

. Ley n. ${ }^{\circ}$ 2.894-Ley de Seguridad Pública, sancionada por la Legislatura de la Ciudad Autónoma deBuenos Aires, 28 de octubre de 2008. Disponible en: www.cedom.gov.ar/es/legislacion/normas/leyes/ley2894.html (Consulta: 2 de marzo de 2009). 


\section{b. Decretos, resoluciones y convenios}

. Decreto n. ${ }^{\circ} 2124 / 04$. Decreto de creación de la Guardia Urbana, en: Boletín Oficial de la Ciudad de Buenos Aires n. 2074, 24 de noviembre de 2004.

. Decreto 94/08. Decreto de disolución de la Guardia Urbana y creación del Cuerpo de Agentes de Control de Tránsito y Transporte (CACTyT), en: Boletín Oficial de la Ciudad de Buenos Aires n. ${ }^{\circ} 2865,7$ de febrero de 2008.

. Decreto n. ${ }^{\circ} 210 / 009$, Decreto Reglamentario de la Ley n. ${ }^{\circ}$ 2.894 (Ley de Seguridad Pública), en: Boletín Oficial de la Ciudad de Buenos Aires n. ${ }^{\circ} 3146,31$ de marzo de 2009.

c. Documentos institucionales y de circulación restringida

. Proyecto de creación de la Guardia Urbana (2004). Subsecretaría de Seguridad Urbana, gobierno de la ciudad de Buenos Aires.
- Informes publicados en el portal web del gobierno de la ciudad de Buenos Aires, área Justicia y Seguridad: Disponible en: http://www.buenosaires.gov.ar/areas/ gobierno/noticias/ (Se tomaron en consideración un total de 15 noticias referidas a la Guardia Urbana, publicadas entre noviembre de 2004 y febrero de 2008).

. Plan de capacitación para la Guardia Urbana. Contenidos mínimos. Subsecretaría de Seguridad Urbana, gobierno de la ciudad de Buenos Aires.

\section{d. Medios gráficos. Dos corpus documentales}

"La Guardia Urbana en la prensa desde su lanzamiento hasta su disolución”. Clarín, Pagina 12 y La Nación (periódicos de circulación nacional), y Noticias Urbanas (publicación electrónica local). Se relevaron un total de 39 noticias.

. "Período 2007/2008, la Guardia Urbana, el problema de la seguridad y una Policía propia”. Clarín, Pagina 12 y La Nación (periódicos de circulación nacional) y Noticias Urbanas (publicación electrónica local). Se relevaron 70 noticias. 
GOVERNMENTALITY AND POLICE

AUTHORITY: the articulation of a dual model of policing in Buenos Aires, 2004-2007

\section{Alina Lis Rios}

This study analyzes the emergence and operation of the Urban Guard (in portugueses, GU) of Buenos Aires, (2004 and 2007), as a police communitary resulting of the reorganization of local government autonomy. This process resulted in a dual model of policing in the city, represented by GU in contraposition to the national security forces, more centralist and verticalized. This paper investigates the implications of GU in the dispute for police authority in the city and a particular historical way of security building: citizen safety. This duality represents a possible compromise between national interests and those of the city. The paper concludes with reflections on the crisis of this dual model, the redefinition of the security problem and the demands of a local "own police". It indicates that it is in the duality of security that an Urban Guard is understood, as a proximity policing that complements but does not replace the old police.

KEYwORDS: governmentality, police authority, public safety, local government, Buenos Aires.
GOUVERNABILITE ET POUVOIR DE LA POLICE: l'articulation d'un modèle de surveillance policière duelle à Buenos Aires, 2004-2007

\section{Alina Lis Rios}

Cet article analyse le surgissement et le fonctionnement de la Garde Urbaine (GU) de Buenos Aires (2004 et 2007), en tant que police communautaire, fruit de la réorganisation de l'autonomie du gouvernement local. Ce processus a abouti à un modèle duel des services de police dans la ville, représenté par la GU, par opposition aux forces de sécurité nationale, plus verticales et centralisatrices. L'article présente une recherche concernant les implications de la GU dans la dispute du pouvoir de la police de la ville et une manière historique particulière d'établir la sécurité: la sécurité citoyenne. Cette dualité est la solution pour un compromis possible entre les intérêts nationaux et ceux de la ville. L'article termine par des réflexions sur la crise de ce modèle duel, la redéfinition du problème de sécurité et les besoins d'une "Police spécifique" sur le plan local. Il montre que c'est dans la dualité de la sécurité que l'on conçoit une Garde Urbaine, en tant que police de proximité, qui complète mais ne remplace pas l'ancienne police.

Mots-CLÉs: Gouvernabilité, pouvoir de police, sécurité publique, pouvoir local, Buenos Aires.

Alina Lis Rios - Socióloga. Doutoranda em Ciências Sociais pela Universidade de Buenos Aires (UBA). Bolsista do CONICET. Membro da equipe de pesquisadores do Programa de Estudios sobre Control Social (PECOS) coordenado pelo Professor Juan Pegoraro no Instituto de Investigaciones Gino Germani. Tem se dedicado ao estudo sobre segurança pública; força policial e políticas de segurança, tendo publicado alguns artigos e capítulos de livros sobre a temática. Dentre as publicações destaca a participação no livro coletivo A la inseguridad la hacemos entre todos (Buenos Aires: Hekht libros, 2010). 